\title{
Atmosphere-Ocean Dynamics of Persistent Cold States of the Tropical Pacific Ocean
}

\author{
Richard SeAger, ${ }^{\mathrm{a}}$ NAOmi Henderson, ${ }^{\mathrm{a}}$ MARk CAne, ${ }^{\mathrm{a}}$ Honghai Zhang, ${ }^{\mathrm{a}}$ AND Jennifer NAKAmurA ${ }^{\mathrm{a}}$ \\ ${ }^{\text {a }}$ Lamont Doherty Earth Observatory of Columbia University, Palisades, New York
}

(Manuscript received 1 September 2020, in final form 17 March 2021)

\begin{abstract}
Persistent multiyear cold states of the tropical Pacific Ocean drive hydroclimate anomalies worldwide, including persistent droughts in the extratropical Americas. Here, the atmosphere and ocean dynamics and thermodynamics of multiyear cold states of the tropical Pacific Ocean are investigated using European Centre for Medium-Range Weather Forecasts reanalyses and simplified models of the ocean and atmosphere. The cold states are maintained by anomalous ocean heat flux divergence and damped by increased surface heat flux from the atmosphere to ocean. The anomalous ocean heat flux divergence is contributed to by both changes in the ocean circulation and thermal structure. The keys are an anomalously shallow thermocline that enhances cooling by upwelling and anomalous westward equatorial currents that enhance cold advection. The thermocline depth anomalies are shown to be a response to equatorial wind stress anomalies. The wind stress anomalies are shown to be a simple dynamical response to equatorial SST anomalies as mediated by precipitation anomalies. The cold states are fundamentally maintained by atmosphere-ocean coupling in the equatorial Pacific. The physical processes that maintain the cold states are well approximated by linear dynamics for ocean and atmosphere and simple thermodynamics.
\end{abstract}

KEYWORDS: Tropics; Atmosphere-ocean interaction; ENSO; La Niña; Ocean circulation; Tropical variability

\section{Introduction}

El Niño-Southern Oscillation is an oscillation of the tropical Pacific atmosphere-ocean system in which the central-toeastern equatorial Pacific Ocean moves between warm and cold states with a characteristic period of 3-7 years. The location and intensity of tropical convection vary with the sea surface temperature (SST) and drive atmospheric Rossby waves that generate seasonal-to-interannual climate variability worldwide. Bjerknes $(1966,1969)$ identified that stronger equatorial easterlies would increase the thermocline tilt, bringing colder waters upward in the eastern equatorial Pacific, and increase equatorial upwelling and, by both processes, cool the east and enhance the zonal SST gradient. The enhanced zonal SST gradient would strengthen the easterly winds and these changes, therefore, occur within a positive atmosphere-ocean feedback. Bjerknes argued that the feedback could explain both El Niño and La Niña events but could not explain how the system went from one state to another but correctly surmised that the "key to the problem may have to be developed by the science of dynamic oceanography" (Bjerknes 1969, p. 170). Later work with observations and models showed that the turnarounds between states indeed arose in the exchange of upper-ocean heat between the equatorial and off-equatorial regions and how this is accomplished by Rossby and Kelvin waves forced by wind stress anomalies and propagating within a closed basin with reflections at the eastern and western boundaries (Cane and Zebiak 1985; Wyrtki 1985; Zebiak and Cane 1987; Zebiak 1989; Neelin et al. 1998; Meehl and $\mathrm{Hu}$ 2006; Wang et al. 2017).

The use of "oscillation" in ENSO implies periodic, linear behavior but in reality, ENSO is anything but. The time scale of oscillations varies from two to seven years, the system has notable multiyear to multidecadal variability, the amplitude of

Corresponding author: Richard Seager, seager@ldeo.columbia.edu events varies with infrequent high-amplitude events and long periods of weak variability, and the spatial patterns of the variability also vary (e.g., Rodgers et al. 2004; Newman et al. 2011; Capotondi et al. 2015; Timmermann et al. 2018; Okumura 2019). Whether these characteristics of ENSO arise from stochastic noise in the climate system or nonlinear dynamics in the ENSO system is a long and ongoing debate [see Timmermann et al. (2018) and references therein]. Also, there tend to be persistent, multiyear cold and warm states. This is shown in Fig. 1 where we plot the Niño-3.4 SST index (SST anomalies averaged over $\left.5^{\circ} \mathrm{S}-5^{\circ} \mathrm{N}, 170^{\circ}-120^{\circ} \mathrm{W}\right)$. Over the past decades, there have been several $\mathrm{El}$ Niño events with rapid rises of SST to strong peaks followed by rapid cooling (e.g., 1972/73, 1982/83, 1997/98, and 2015/16) whereas there was only one similarly sharp cold event (1988). However, there were several extended events with cold SST anomalies of lesser amplitude (marked in Fig. 1) such as in the early 1960s, early 1970s, mid-1980s, the turn of the century, and in the early years of the 2010s. These all begin with a rapid transition out from an El Niño event and tend to end with a gradual transition back to warm conditions. This El Niño-to-La Niña transition followed by multiyear duration of La Niña has been noted before (Okumura et al. 2011; Kohyama and Hartmann 2017). Key explanations for rapid warm-to-cold transitions and the more gradual move out of cold conditions are the zonal wind response to warm SST anomalies being stronger than to cold anomalies (Ohba and Ueda 2009; Frauen and Dommenget 2010; Dommenget et al. 2012) and nonlinearities in the relation between thermocline depth and the temperature of upwelled water (DiNezio and Deser 2014).

In Fig. 1 we also show similarly identified (see below for the criteria) warm states. There have been two extended warm states in recent history in the early 1990s (Trenberth and Hoar 1996; Goddard and Graham 1997; Latif et al. 1997) and in the mid-2000s. Over the full period of instrumental SST records 
4 Month Averaged NINO3.4
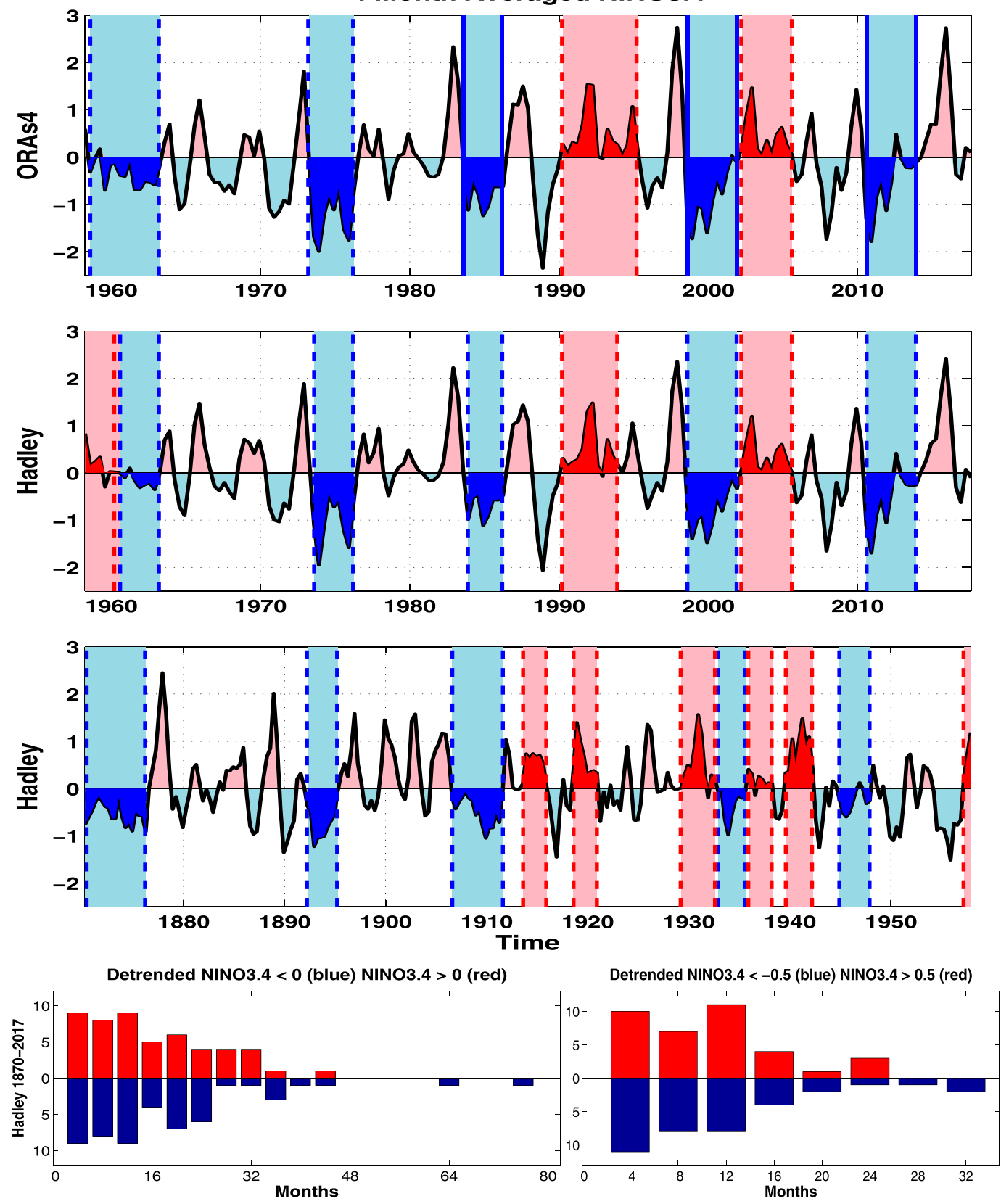

FIG. 1. The Niño-3.4 SST index in non-overlapping 4-month averages (top) from June 1958 to September 2017 from ECMWF and (top middle),(bottom middle) from June 1870 to September 2017 from Hadley Centre data. The persistent cold states, defined as periods of more than 30 months with no more than one 4-month period within that has an above-zero Niño-3.4 value, are marked between dashed and solid vertical lines with blue shading in between. Similarly identified warm states are marked by vertical lines and red shading. The solid lines denote the three cold states in the post-1979 period studied using the ECMWF data. (bottom) Counts with the detrended longer Hadley data of cold (below the zero $x$ axis and blue) and warm (above the zero $x$ axis and red) states of the length in months indicated using the deviation from (left) a $0^{\circ} \mathrm{C}$ criterion and (right) below $-0.5^{\circ}$ and above $0.5^{\circ} \mathrm{C}$ criteria.

there have only been slightly more multiyear cold states (10) than warm states (8). Hence it is not immediately clear that the tropical Pacific coupled system is asymmetric in the frequency of warm and cold states.
Here our focus is not on asymmetries in the ENSO system but on the atmosphere-ocean dynamics of the persistent cold states. Our focus on the persistent cold states of the tropical Pacific Ocean is motivated by their tendency to be associated 


\section{Extended La Niña Periods}

\section{Precipitation, $200 \mathrm{hPa}$ Heights Precip, SSTA, 700 hPa Heights \\ June 1983 - May 1986}
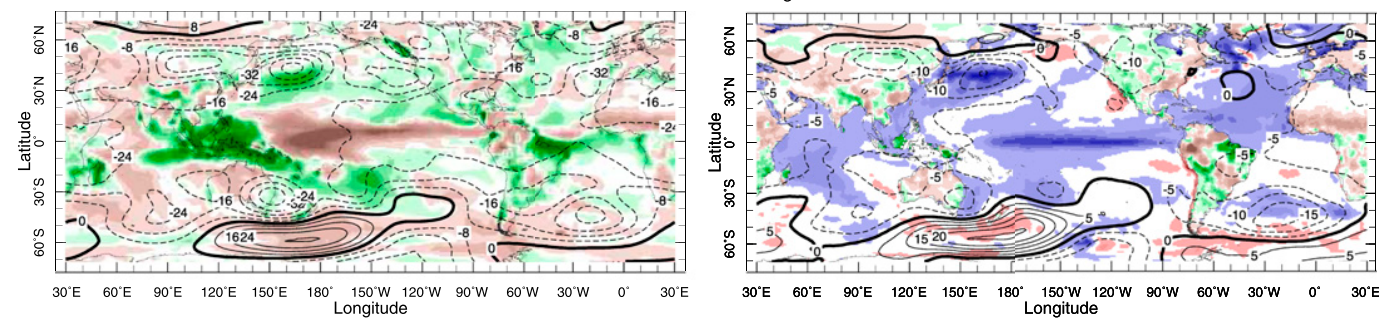

June 1998 - January 2002
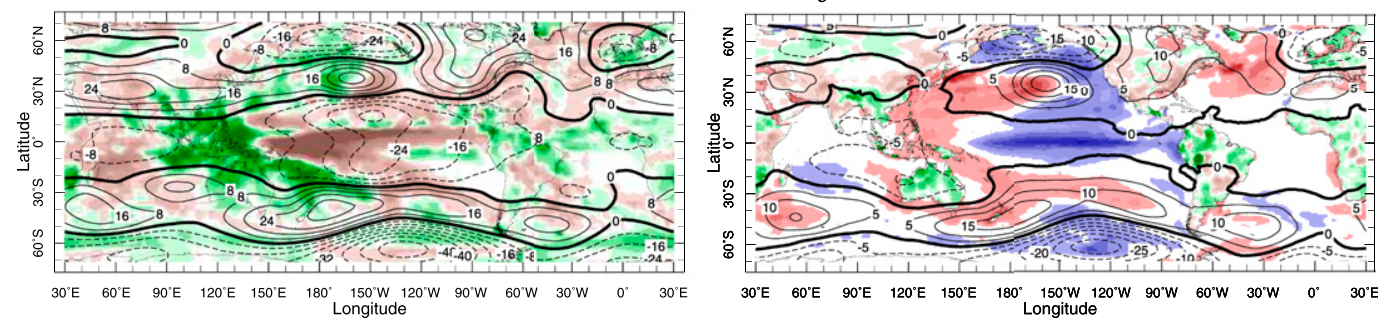

June 2010 - January 2014
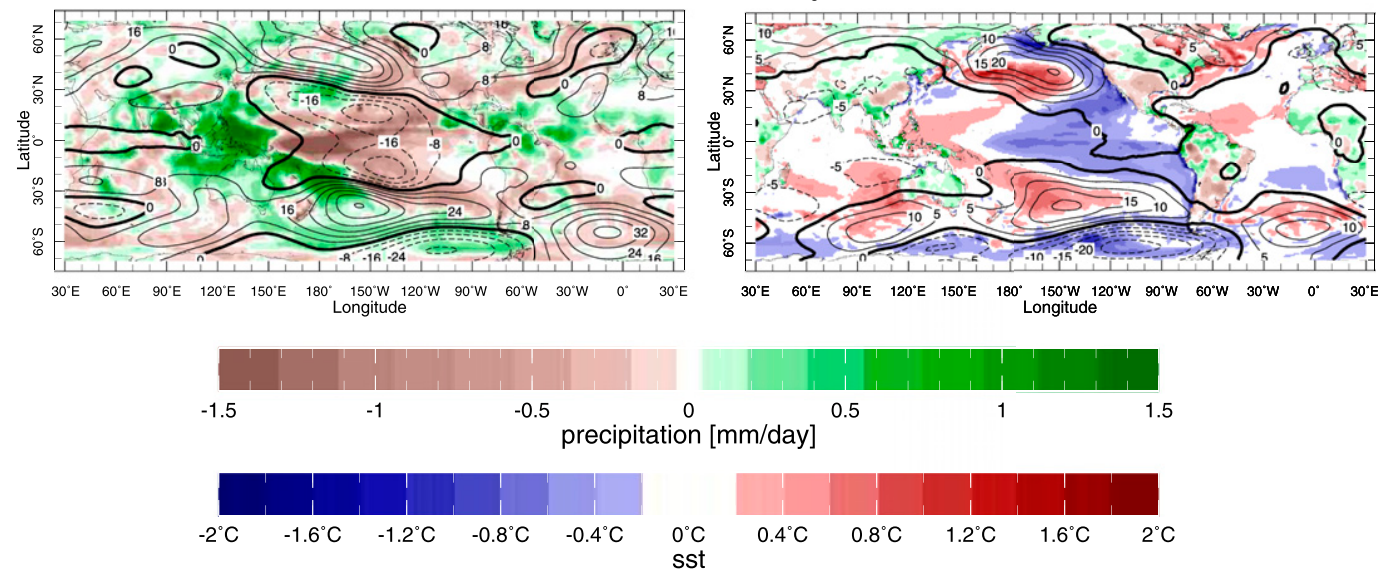

FIG. 2. The anomalous atmosphere-ocean conditions averaged throughout the tropical Pacific cold states for the three states of (top) 1983-86, (middle) 1998-2002, and (bottom) 2010-14. (left) GPCP satellite-gauge precipitation (colors; mm day ${ }^{-1}$ ) and 200-hPa heights (contours; m). (right) CRU 3.25 gauge-based precipitation (colors over land; $\mathrm{mm} \mathrm{day}^{-1}$ ), SST (colors over the ocean; K), and 700-hPa heights (contours; $\mathrm{m}$ ).

with equally persistent dry states in the Great Plains and southwest North America. Cold states have been implicated in causing the Dust Bowl of the 1930s and similarly long droughts in the late 1940s to mid-1950s and at the turn of the twenty-first century and three in the mid- to late nineteenth century (Schubert et al. 2004a,b; Seager et al. 2005b; Herweijer et al. 2006; Herweijer and Seager 2008). It has been argued that the cold states also drive persistent hydroclimate anomalies elsewhere including drought in the Mediterranean (Hoerling et al. 2012), extratropical South America (Herweijer and Seager 2008; Seth et al. 2015), and East Africa (Lyon and DeWitt 2012) and wet conditions in northeast
Brazil (Seager 2015). These hydroclimate anomalies fall into a spatial pattern akin to that in a La Niña event and are explainable in terms of Rossby wave teleconnections, poleward shifts of the jet streams and storm tracks, and tropical tropospheric cooling (e.g., Seager et al. 2005a; see also Fig. 2 herein, which is discussed more below).

Our goal here is to understand the dynamical and thermodynamical state of the tropical Pacific atmosphere-ocean system during the cold states. We aim to do the following:

- determine how the cold SST anomalies are maintained in terms of changes in the ocean circulation, upper-ocean 
thermal structure, ocean temperature, and surface heat fluxes;

- understand how these persistent anomalies in the ocean state are maintained by wind anomalies and where the wind anomalies are important; and

- understand if the wind anomalies over the tropical Pacific that sustain the cold states can be reproduced as a response to the tropical Pacific SST anomalies alone.

The third point arises in the context of the considerable literature about influences of the Indian Ocean and Atlantic and extratropical Pacific on the tropical Pacific (Cai et al. 2019) but specifically addresses maintenance of the long-lived cold states. For example, if the winds over the tropical Pacific during the cold states were being partly driven by concurrent SST anomalies in the Indian, Atlantic, or extratropical Pacific Oceans then they would not be able to be reproduced as a response to tropical Pacific SST anomalies alone. The work is done using a combination of atmosphere and ocean reanalyses and simple linear dynamical models of the tropical Pacific Ocean and atmosphere. We begin with a heat budget analysis following a long history of similar work using buoy data (e.g., Wang and McPhaden 2000, 2001), ocean reanalyses (e.g., An and Jin 2004; Huang et al. 2012), and numerical models (e.g., Menkes et al. 2006). The results are used to construct and test simplified models of ocean circulation and SST to identify the dominant processes that maintain the cold states. Finally, we partially couple the best performing simple ocean model to a simple atmosphere model and show that the cold states persist due to self-reinforcing feedbacks between the equatorial Pacific atmosphere and ocean.

\section{Data, models, and methodology}

\section{a. Atmosphere and ocean data}

Data for atmosphere and ocean come from the European Centre for Medium-Range Weather Forecasts (ECMWF) reanalyses: ERA-Interim for the atmosphere, and Ocean Reanalysis System 4 (ORAS4) for the ocean (Dee et al. 2011; Balmaseda et al. 2013). We use the 1979-2017 period when satellite data are available for assimilation into the reanalyses. These reanalyses are consistent in that the surface forcing for ORAS4 was taken from ERA-Interim and the SST forcing for ERA-Interim was taken from ORAS4. Also, for analysis of global precipitation during cold states we use the satellite-gauge Global Precipitation Climatology Project (GPCP) product (Huffman et al. 2001) and the Climatic Research Unit land-only gauge product 3.25 (Harris et al. 2014). For a longer-term perspective on cold states we analyzed the Hadley Center Sea Ice and Sea Surface Temperature (HadISST) data available at https://www.metoffice.gov.uk/hadobs/hadisst/ (Rayner et al. 2003).

\section{b. Simplified ocean and atmosphere models}

To understand the mechanisms that maintain the cold states we conduct experiments with the simple ocean and atmosphere models of Seager et al. (2019) with some modifications. The ocean model follows from that of Seager et al. (1988) and Blumenthal and Cane (1989). The upper-ocean circulation is represented by frictional, time-dependent, linear shallow water equations for the first two vertical modes forced by surface wind stress. The surface wind is directly felt within a uniform 50-m-deep surface Ekman layer and evaluated with a steady balance between Rayleigh friction, the Coriolis force, and surface stress. Given that the Ekman flow can be considered as the sum over all the higher-order vertical modes (Blumenthal and Cane 1989), the total surface flow is the sum of the Ekman component and the surface flow given by the two vertical modes. The divergence of the surface flow integrated over the mixed layer depth equals the upwelling at 50-m depth. The temperature of the water entrained into the mixed layer is parameterized in terms of the thermocline depth with the fit developed using the ECMWF data for temperature at 50-m depth, $T_{50}$, and modeled thermocline depth. This parameterization is developed and applied only in the equatorial Pacific Ocean $\left(5^{\circ} \mathrm{S}-5^{\circ} \mathrm{N}\right)$. The ocean model is the global version of the shallow water equations with realistic coastlines as in Israeli et al. (2000). It is named the Tropical Climate Ocean Model (TCOM).

The atmosphere model of Seager et al. (2019) assumes the flow is governed by steady frictional dynamics in a single baroclinic vertical mode between the surface and a tropospheric top as in Gill (1980). The flow is driven by relaxation of temperature to the SST and heating associated with precipitation and latent heat release in deep convection following Davey and Gill (1987) and Seager (1991). The precipitation itself is modeled differently than in Seager et al. (2019), who used a simplified moisture budget. Instead, here we follow Johnson and Xie (2010) and Okumura (2019) and assume that precipitation occurs only where the total SST exceeds the tropical Pacific basin mean $\left(30^{\circ} \mathrm{S}-30^{\circ} \mathrm{N}\right)$ and then is linearly proportional to the total SST departure from the basin mean at the rate of $4 \mathrm{~mm}$ day ${ }^{-1} \mathrm{~K}^{-1}$. With this difference in heating parameterization we found that a half-day relaxation of temperature to SST provided the best stress simulation. Surface winds within the baroclinic mode are converted into surface wind stress anomalies using a bulk formula and the imposed climatological mean wind speed and direction. For this study, the atmosphere model is only forced by tropical Pacific SST anomalies, thus excluding any direct influence on the winds from SSTs outside that region. The model is named the Tropical Climate Atmosphere Model (TCAM).

Although we do not use a fully coupled model here, we do examine the ocean response to the modeled atmospheric state and the atmospheric response to the modeled ocean state. In these cases, the atmosphere model responds to the modeled SST and the ocean model responds to modeled wind stress anomalies. The experiments simulate the cold states initialized from 1 January of the preceding El Niño. The initial conditions are the observed SST while the ocean currents and thermocline depth come from a run of the ocean model driven by observed wind stresses that was begun in January 1958 and continued through 2017.

\section{c. Identification and characterization of persistent cold states}

The cold states were identified based on the Niño-3.4 SST index for both the SST datasets. To identify variability longer 
than monthly we first compute non-overlapping 4-month means from October 1958 to September 2017. Persistent cold states are then periods longer than 30 months for which all, or all but one, of the contained 4-month mean Niño-3.4 values are below zero. The beginning and end months are identified. This method is chosen to ensure that 1) at least three events to analyze in the better-observed post-1979 period, and that 2) the cold states are long enough to cause persistent drought impacts. We recognize that the selection methodology is somewhat arbitrary in that different criteria could easily be chosen for other purposes. As seen in Fig. 1, the states identified are the same for the overlapping period in both the ECMWF and Hadley Centre SST datasets. The global atmosphere-ocean state during the cold states are illustrated by the average from the beginning to the end of the event the SST, precipitation (GPCP for land and ocean, CRU for land only) and 200- and 700-hPa height anomalies. We only examine the three states in the post-1979 period and these are marked in Fig. 1. Warm states identified by the same method are also shown in Fig. 1 but are not studied here.

\section{d. Ocean mixed layer heat budget}

The ocean mixed layer heat budget is evaluated using temperatures and velocities on the layers of ORAS4 and follows DiNezio et al. (2009). The temperature equation is integrated vertically to a depth of $50 \mathrm{~m}$. The mixed layer depth was computed in ORAS4 using a density jump criterion and is shallower than $50 \mathrm{~m}$ in the east and west equatorial Pacific and deeper in the central equatorial Pacific so the 50-m choice is reasonable and consistent with the simple uniform depth mixed layer used in the ocean modeling work. To determine processes we divide velocities and temperatures into climatological monthly means, indicated by overbars, and anomalies (departures from the climatological monthly means), indicated by primes. This allows us to divide contributions to SST tendency into those due to anomalies in currents and those due to anomalies in ocean temperature. Thermocline depth anomalies, although dynamical, create temperature anomalies at any given depth. The heat budget equation is then as follows:

$$
\rho c_{p} \int_{H}^{0} \frac{\partial T^{\prime}}{\partial t} d z=Q_{\mathrm{ocn}, \mathrm{DYN}}+Q_{\mathrm{ocn}, \mathrm{TH}}+Q_{\mathrm{ocn}, \mathrm{NL}}+Q_{\mathrm{sfc}}^{\prime}+Q_{\mathrm{sgs}}^{\prime}
$$

In the above equation, $T^{\prime}$ is temperature anomaly, $z$ is depth positive downward, $H$ is the upper layer depth taken to be $50 \mathrm{~m}, \rho$ is density of seawater, $c_{p}$ is the specific heat of seawater, and $Q_{\text {sfc }}^{\prime}$ is the net surface heat flux anomaly; $Q_{\text {sgs }}^{\prime}$ is computed as a residual and represents anomalous heat flux convergence due to submonthly time scale covariability of velocity and temperature as well as unresolved subgrid-scale processes that primarily consist of horizontal and vertical mixing by eddies, including tropical instability waves. Since it is a residual, it will also include any tendencies introduced in the assimilation process and any imbalances, for example, due to chosen numerical methods and those not matching the ones used within ORAS4 . Nevertheless, $Q_{\text {sgs }}$ acts primarily as a damping of ocean temperature anomalies as expected if it is dominated by eddies (Wang and McPhaden 2000, 2001). All terms are in familiar units of watts per square meter. The first three terms on the RHS of Eq. (1) are the dynamical $Q_{\text {ocn,DYN, thermody- }}$ namical $Q_{\mathrm{ocn}, \mathrm{TH}}$, and nonlinear mixed dynamical-thermodynamical $Q_{\text {ocn,NL }}$ terms. These respectively represent contributions to the anomalous ocean heat flux convergence due to change in circulation with climatological temperature, change in temperature with climatological circulation, and the combined effects of anomalies in temperature and circulation. These terms can be written as follows:

$$
\begin{aligned}
Q_{\mathrm{ocn}, \mathrm{DYN}} & =\rho c_{p} \int_{H}^{0}\left[\left(u^{\prime} \frac{\partial \bar{T}}{\partial x}+v^{\prime} \frac{\partial \bar{T}}{\partial y}+w^{\prime} \frac{\partial \bar{T}}{\partial z}\right)\right] d z, \\
Q_{\mathrm{ocn}, \mathrm{TH}} & =\rho c_{p} \int_{H}^{0}\left[\left(\bar{u} \frac{\partial T^{\prime}}{\partial x}+\bar{v} \frac{\partial T^{\prime}}{\partial y}+\bar{w} \frac{\partial T^{\prime}}{\partial z}\right)\right] d z, \\
Q_{\mathrm{ocn}, \mathrm{NL}} & =\rho c_{p} \int_{H}^{0}\left[\left(u^{\prime} \frac{\partial T^{\prime}}{\partial x}+v^{\prime} \frac{\partial T^{\prime}}{\partial y}+w^{\prime} \frac{\partial T^{\prime}}{\partial z}\right)\right] d z .
\end{aligned}
$$

Here $u, v$, and $w$ are zonal, meridional, and vertical velocity; $Q_{\mathrm{ocn}}=Q_{\mathrm{ocn}, \mathrm{DYN}}+Q_{\mathrm{ocn}, \mathrm{TH}}+Q_{\mathrm{ocn}, \mathrm{NL}}$ is the total anomalous ocean heat flux convergence contribution to the upper-ocean heat content tendency. Terms were evaluated using simple centered differences. For the vertical advection, vertical velocity at layer interfaces is multiplied by a centered difference estimate of the vertical temperature gradient using temperature at midlevels and then vertically integrated with a trapezoidal method. Since the vertical temperature gradient is small within the mixed layer this term will only become important when the depth of integration extends below the mixed layer and incorporates the temperature jump at mixed layer base. Although it is included in $Q_{\text {ocn }}$, the nonlinear term involving covariances between monthly mean circulation and temperature anomalies was smaller than the dynamical, thermodynamical, and surface heat flux terms. It will be neglected hereafter.

\section{Results}

\section{a. Global atmosphere-ocean regimes during persistent cold states}

Figure 2 shows the SSTs, precipitation, and 200- and 700-hPa height anomalies averaged over the cold states for each of the three events as recorded in the ECMWF reanalysis data. We have not detrended these quantities so anomalies of SST and heights contain the signal of steady warming of the oceans and atmosphere and, hence, increasing heights. The cold states have La Niña-like SST patterns with anomalies extending across most of the equatorial Pacific. In the 1983-86 event, there is a cold SST anomaly east of Japan that is not evident in the later two events and is likely of origin independent from the cold states. In all cases geopotential heights are low along the equator and in the later two cases there are signs of the typical La Niña teleconnection patterns with midlatitude ridges. These are somewhat evident in the 1983-86 event in the Southern Hemisphere but many of the northern extratropical circulation anomalies during this period do not clearly show the imprint of 
cold tropical Pacific conditions. All of the cold states have reduced precipitation over the equatorial Pacific Ocean above the cold SST anomalies. They also have enhanced precipitation over the Maritime Continent and Southeast Asia and parts of equatorial Brazil. Cold equatorial Pacific SSTs tend to induce increased precipitation over the Sahel. This does occur in the 1998-2002 and 2010-14 cold states but not in the 1983-86 event. Instead, dry conditions in the Sahel during 1983-86 are consistent with the colder than normal North Atlantic Ocean (e.g., Giannini et al. 2003). In the extratropics, we expect cold SSTs in the equatorial Pacific to drive drought in the American Southwest and also in South America (e.g., Seager 2015). This did occur in southwest North America in the 1998-2002 and 2010-14 events, which were associated with well-known highimpact droughts (Cole et al. 2002; Hoerling and Kumar 2003; Cook et al. 2007; MacDonald 2007; Seager 2007; McCabe et al. 2008; Weiss et al. 2009; Seager et al. 2015, 2017) but not during the 1980 s event, consistent with the circulation anomalies not appearing to be tropically driven. In the 1998-2002 and 201014 events, droughts did occur in Chile and were widespread across midlatitude South America in 2010-14 (Seth et al. 2015; Garreaud et al. 2018).

\section{b. Cold states and warm states}

Do cold states arise from an asymmetry in the tropical Pacific SST variability? Looking at either the shorter ECMWF or longer Hadley SST data (Fig. 1) it is clear that there are persistent cold states throughout the record including in the nineteenth century when in the 1870 s and 1890 s they were associated with serious North American droughts (Herweijer et al. 2006). It is also clear that there are persistent warm states, for example in the early to mid-1990s (Trenberth and Hoar 1996; Goddard and Graham 1997; Latif et al. 1997). The lower panels of Fig. 1 show the length in months of consecutive periods with the Niño-3.4 SST below or above zero (at left) and below $-0.5^{\circ} \mathrm{C}$ or above $0.5^{\circ} \mathrm{C}$ (at right), which accounts for event intensity, based on the detrended Hadley data. There is a slight hint that the longest states might be more common for cold states than warm states but any warm-cold asymmetry in the coupled system is not obvious by this measure. Our focus remains on the cold states because of the drought association in the extratropical Americas.

\section{c. Dynamical and thermodynamical mechanisms for the maintenance of cold states}

1) DiAgNOSIS OF THE CONTRIBUTIONS OF DYNAMICAL, THERMODYNAMICAL, SURFACE HEAT FLUX, AND SUBGRID-SCALE PROCESSES TO THE MAINTENANCE OF COLD STATES

Figure 3 shows Hovmöller diagrams of SST, zonal wind stress, precipitation, $T_{50}$, and thermocline depth, taken to be the depth of the $20^{\circ} \mathrm{C}$ isotherm $h_{20}$, averaged over $5^{\circ} \mathrm{S}-5^{\circ} \mathrm{N}$ for the three cold states, the El Niños that precede them, and the return to warm conditions. There is a commonality across the three events. After the warm event, each cold state is characterized by cold SSTs that persist for a few years but can occasionally approach neutral conditions or even briefly warm (as in 2012). The cold SSTs extend across the Pacific from $150^{\circ} \mathrm{E}$ to the coast of the Americas. Cooling is frequently below $-1^{\circ} \mathrm{C}$. The SST cooling is matched by cooling of $T_{50}$; that is, the subsurface waters are also cool during the persistent cold states. This is related to a shallower thermocline (negative values of $h_{20}$ ) in the central to eastern equatorial Pacific, which brings cold water closer to the surface available to be upwelled into the mixed layer. Typically the thermocline is anomalously deep in the western equatorial Pacific; that is, during the cold states the zonal tilt of the thermocline is greater than normal. In the atmosphere, during the cold states, there is reduced precipitation centered just west of the date line. The reduced precipitation is collocated with easterly wind stress anomalies that last throughout the cold states.

These results suggest that the cold SSTs have a dynamical origin in the shallowing of the thermocline in the central and eastern equatorial Pacific. The enhanced thermocline tilt is driven by persistent easterly wind stress anomalies. These are related to reduced central to west Pacific precipitation anomalies that have the effect of moving the locus of the Indo-west Pacific warm pool precipitation farther west and along with it extending the Walker circulation easterlies westward. The precipitation anomalies themselves are a response to the central Pacific cooling. This appears to be a self-consistent atmosphereocean state. Further understanding can come from analyzing the upper-ocean heat budget.

Figures 4-6 provide results of the upper-ocean reanalysis heat budget analysis for each of the three cold states. We show the SST, the total ocean heat flux convergence, its dynamical and thermodynamical components, the surface heat flux, and the subgrid-scale contributions to the heat content tendency [Eqs. (1) and (2)]. For each of the three cold states, the cold SSTs correspond to an ocean heat flux divergence anomaly (top middle) and are opposed by a warming tendency due to surface heat fluxes (bottom middle). These relations indicate that the cold states are dynamically driven and damped by increased heat flux from the atmosphere. For each cold state, both changes in circulation (top right) and ocean thermal structure (bottom left) make substantial cooling contributions to the anomalous ocean heat flux convergence. The cold SST anomalies are also opposed by a subgrid-scale warming tendency (bottom right), which is consistent with the damping effect on SST anomalies of tropical instability waves as reported by Wang and McPhaden (2000, 2001).

\section{2) FUNDAMENTAL OCEAN PROCESSES DURING COLD STATES}

Anomalous ocean heat flux convergence drives the cold states but it is possible to use the heat budget analysis and simplified modeling to understand more precisely what aspects of ocean circulation and temperature change are truly essential to maintaining the cold states. Each of the individual terms in Eq. (1) was computed from the ECMWF reanalysis to determine which terms and processes were dominant. It was found that, of the mean flow terms, anomalous advection of the mean zonal temperature gradient by the anomalous zonal current, advection of the anomalous meridional temperature gradient by the mean meridional flow, and advection of the anomalous 
ECMWF anomalies, $5^{\circ} S-5^{\circ} \mathrm{N}$ average

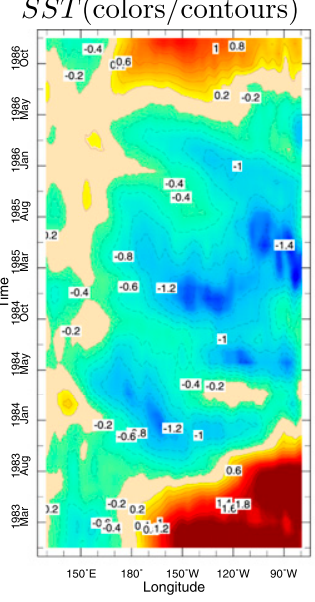

1983-1986

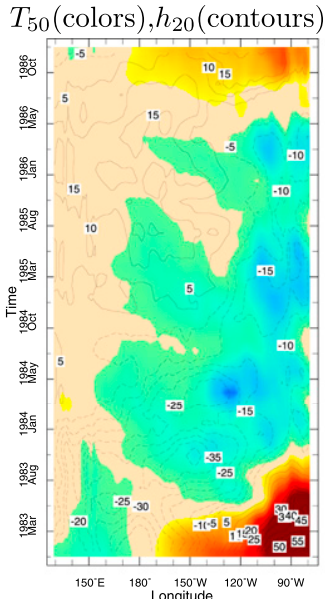

$P($ colors $), \tau^{x}$ (contours)

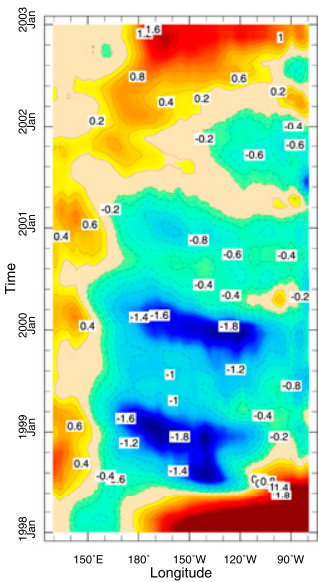

1998-2002
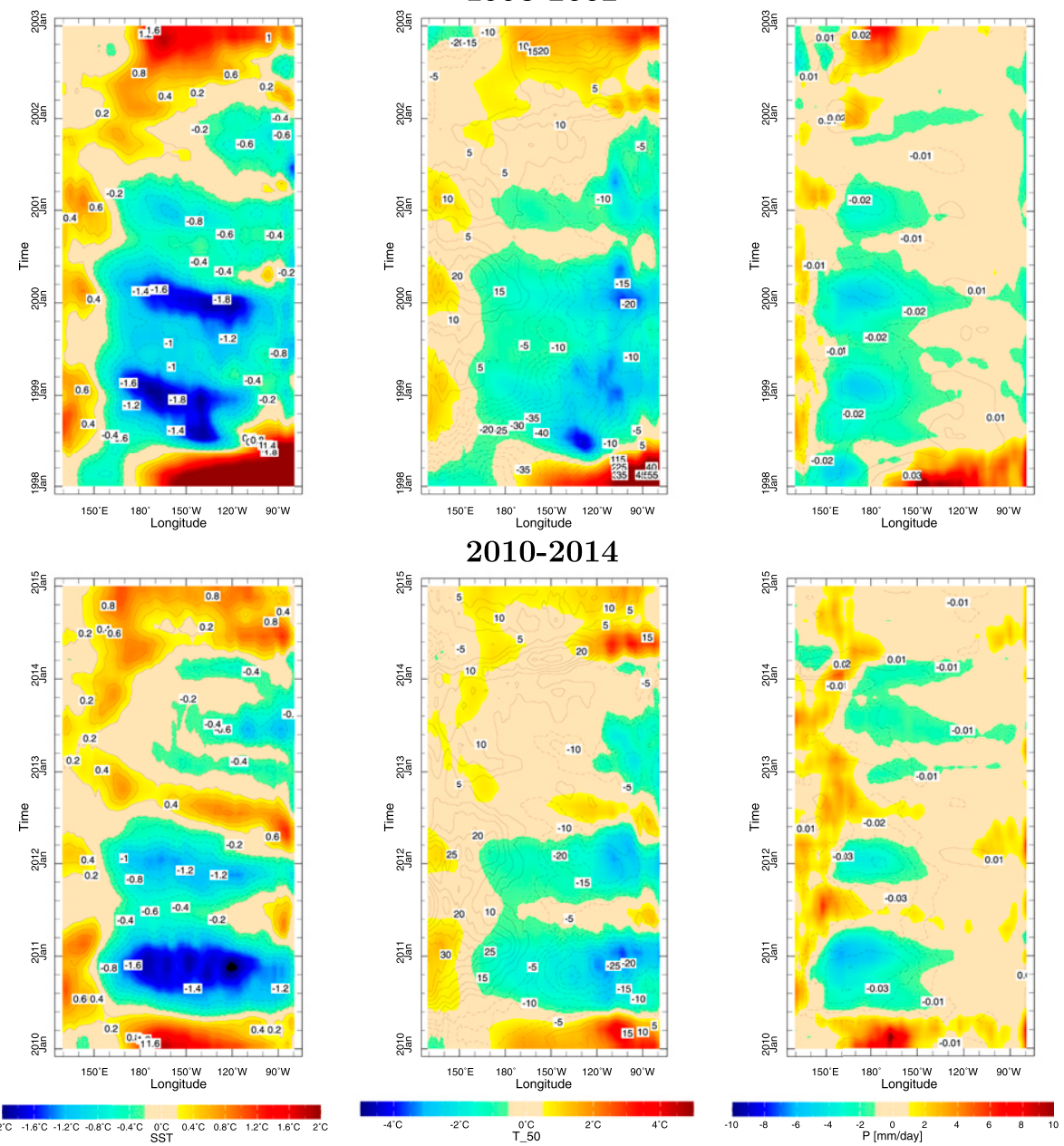

FIG. 3. Hovmöller diagrams of anomalies of ocean and atmosphere quantities averaged over $5^{\circ} \mathrm{S}-$ $5^{\circ} \mathrm{N}$ for the three cold states of (top) 1983-86, (middle) 1998-2002, and (bottom) 2010-14 from ECMWF reanalysis data. (left) SST (colors and contours; K), (center) temperature at 50-m depth $\left(T_{50}\right.$; colors; K) and thermocline depth $\left(h_{20}\right.$; contours; $\left.\mathrm{m}\right)$, and (right) precipitation $(P$; colors; $\left.\mathrm{mm} \mathrm{day}{ }^{-1}\right)$ and zonal wind stress $\left(\tau^{x}\right.$; contours; $\left.\mathrm{kg} \mathrm{m}^{-2} \mathrm{~s}^{1}\right)$. 


\section{Heat Budget Anomalies 1983-1986}
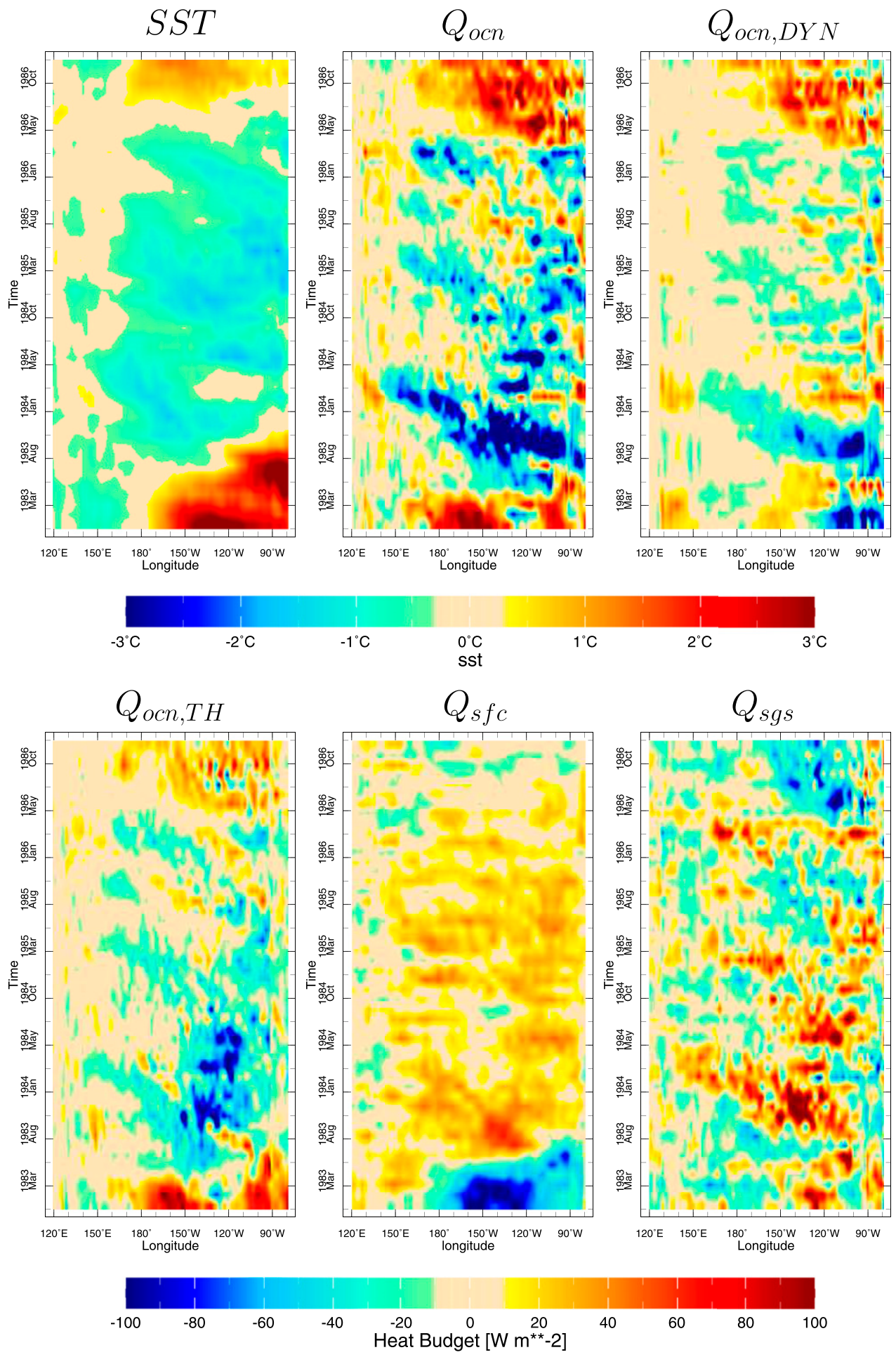

FIG. 4. Hovmöller plots of ECMWF SST and components of the upper-50-m ocean heat budget during the 1983-86 cold state. Shown are (top left) SST (K) and (top center) heat content tendency ( $\mathrm{W} \mathrm{m}^{-2}$ ) due to ocean heat transport convergence, and their decomposition into components due to (top right) circulation change and (bottom left) ocean temperature change, (bottom middle) net surface heat flux, and (bottom right) subgrid-scale processes. 


\section{Heat Budget Anomalies 1998-2002}
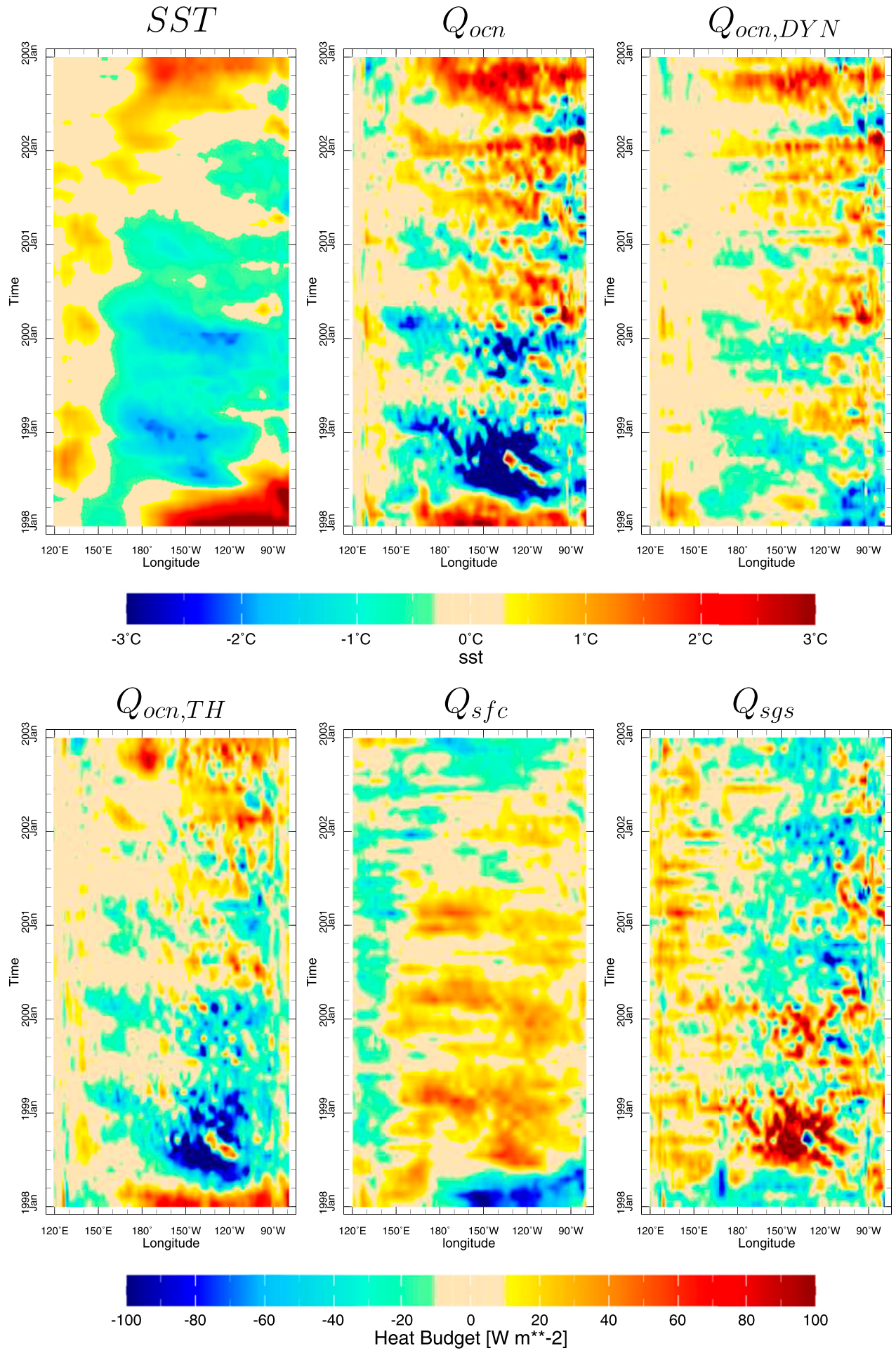

FIG. 5. As in Fig. 4, but for the 1998-2002 cold state. 


\section{Heat Budget Anomalies 2010-2014}
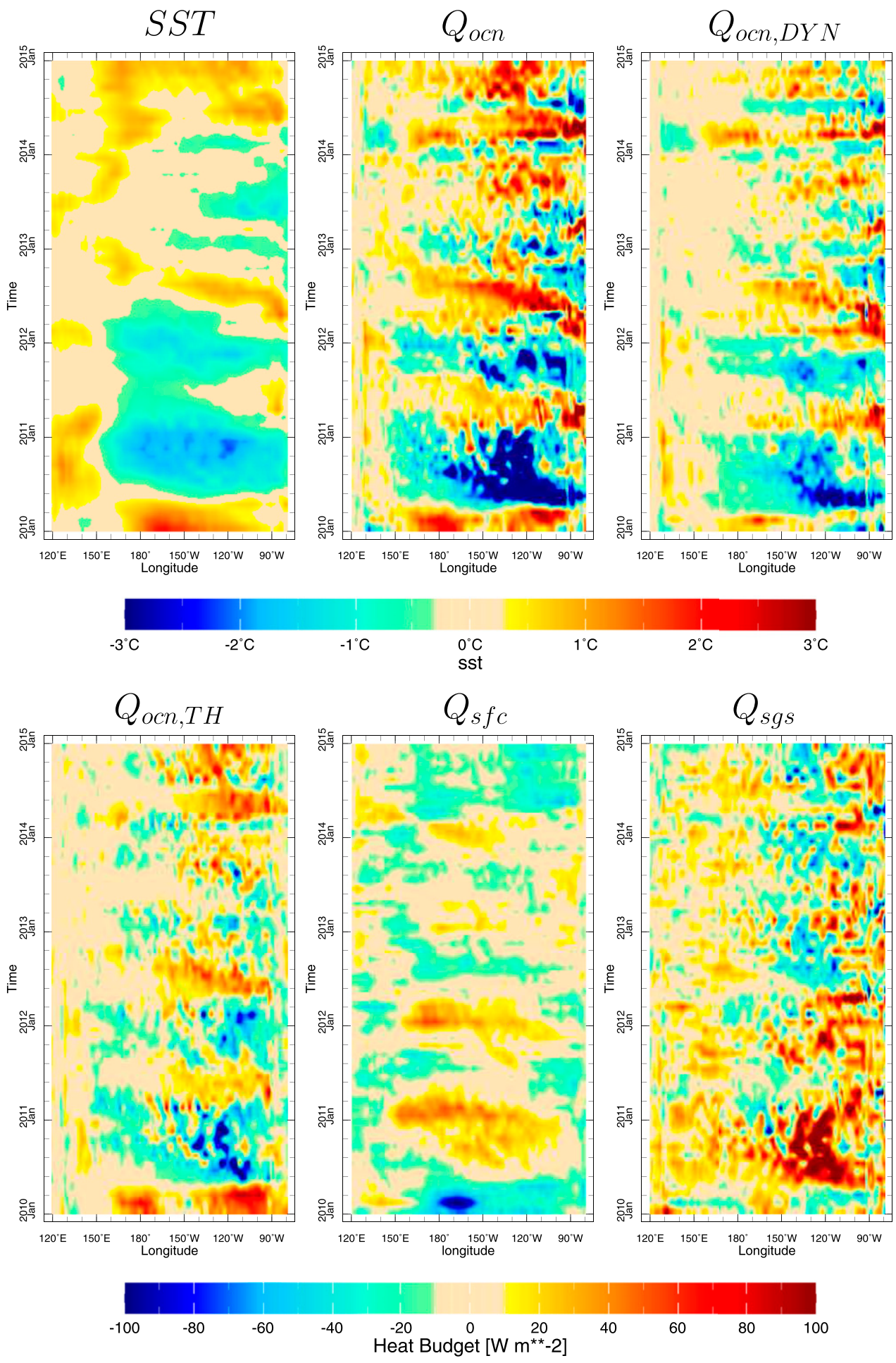

FIG. 6. As in Fig. 4, but for the 2010-14 cold state. 
vertical temperature gradient by the mean upwelling were the leading terms. Less important were the advection of the anomalous zonal SST gradient by the mean zonal current, advection of the mean meridional temperature gradient by the anomalous meridional current, and advection of the mean vertical temperature gradient by the anomalous upwelling. The surface heat flux damps the SST and the nonresolved subgrid-scale processes also opposed the SST tendency due to mean flow ocean heat flux convergence. This knowledge is used to test simple ocean models of the mechanisms of cold states. The simplified ocean models only contain the three advection terms identified from ORAS4 as to be leading and we represent the surface heat flux as a simple damping on SST and subgrid-scale processes as a Laplacian diffusion of SST, respectively. To further simplify matters we compute SST for a 50-m-depth mixed layer in which the currents and temperature are assumed to have their surface values. Hence the vertical advection term is replaced with entrainment of water into the mixed layer using the vertical velocity at $50 \mathrm{~m}$ and temperature at $50-\mathrm{m}$ depth, $T_{50}$.

\section{(i) Simplified ocean model with reanalysis currents}

The first simple ocean model solves for $T_{\mathrm{SM}, E}^{\prime}$, the SST anomaly using surface layer (denoted by subscript $s$ ) currents and upwelling, mean SST, and $T_{50}$, all taken from ECMWF as denoted by subscript $E$, according to the SST equation:

$$
\begin{aligned}
\frac{\partial T_{\mathrm{SM}, E}^{\prime}}{\partial t}= & -u_{s, E}^{\prime} \frac{\partial \bar{T}_{E}}{\partial x}-\bar{v}_{s, E} \frac{\partial T_{\mathrm{SM}, E}^{\prime}}{\partial y}-\frac{\bar{w}_{s, E}}{H}\left(T_{\mathrm{SM}, E}^{\prime}-T_{50, E}^{\prime}\right) \\
& -\alpha T_{\mathrm{SM}, E}^{\prime}+\kappa \nabla^{2} T_{\mathrm{SM}, E}^{\prime}+F^{\prime} / \rho c_{p} H .
\end{aligned}
$$

Here $\alpha$ is a Newtonian damping coefficient and $\kappa$ is a diffusion coefficient; $F^{\prime}$ is the radiative forcing anomaly due to rising greenhouse gases, which is modeled as in Seager et al. (2019) with $F^{\prime}=\left(1-a C^{2}\right) f_{1}^{\prime} \varepsilon \sigma \bar{T}_{E_{s}}^{4}$, where $C$ is annual mean cloud cover, $\varepsilon$ is the emissivity of the sea surface, $\bar{T}_{E}$ is the climatological mean SST, $a=0.62$, and $f_{1}^{\prime}$ is a greenhouse parameter adjusted to give a reasonable change in downward longwave radiation due to the rise in $\mathrm{CO}_{2}$ in the absence of water vapor feedback.

\section{(ii) Simplified ocean model with shallow water equation dynamics}

Our next step is to assess if we can simplify the dynamics by using the TCOM ocean model of Seager et al. (2019) with shallow water dynamics and a frictional Ekman layer.

\section{DEPENDENCE OF EQUATORIAL THERMOCLINE DEPTH ON WIND STRESS}

The analysis to date suggests that explaining the cold states will require explaining the shallower equatorial thermocline. But what does the equatorial thermocline depth depend on in terms of wind stress? Based on theory (e.g., Emile-Geay and Cane 2009) we suspect it is the zonal wind stress only and that near the equator is the most important. Figure 7 shows Hovmöller diagrams of the thermocline depth variations during the cold states for the case with zonal and meridional wind stress anomalies applied to the shallow water model everywhere and for the case of driving only by zonal wind stress anomalies over the Pacific Ocean between $10^{\circ} \mathrm{S}$ and $10^{\circ} \mathrm{N}$. At first glance, it might seem we have made a plotting error so similar are the two modeled thermocline depths. However, there are small differences. This does, however, emphasize that the equatorial thermocline anomalies are almost entirely driven by zonal wind stress anomalies near the equator.

\section{SIMPLIFIED OCEAN MODEL FOR SST}

For calculating ocean circulation we, therefore, only use zonal wind stress in the equatorial Pacific as forcing. In the first case, with SST anomalies denoted with subscript $T 1$, we use the zonal current anomaly $u_{s, T 1}$ directly from the TCOM model, which will include Ekman and geostrophic components. Mean meridional currents and upwelling are also computed by TCOM. The temperature of the water upwelled into the mixed layer $T_{50, T}$, is computed in terms of the thermocline depth modeled by TCOM (see Seager et al. 2019). Quantities computed by TCOM have the subscript $T$.

$$
\begin{aligned}
\frac{\partial T_{T 1}^{\prime}}{\partial t}= & -u_{s, T 1}^{\prime} \frac{\partial \bar{T}_{E}}{\partial x}-\bar{v}_{s, T} \frac{\partial T_{T 1}^{\prime}}{\partial y}-\bar{w}_{s, T}\left(T_{T 1}^{\prime}-T_{50, T}^{\prime}\right) \\
& -\alpha T_{T 1}^{\prime}+\kappa \nabla^{2} T_{T 1}^{\prime}+F^{\prime} / \rho c_{p} H .
\end{aligned}
$$

In the second version, denoted by subscript $T 2$, we replace the zonal current anomaly computed by TCOM with that induced solely by a frictional balance on the equator $(f=0)$ with the zonal wind stress, namely $r u_{s, T 2}^{\prime}=\tau_{x}^{\prime} / \rho H$.

$$
\begin{aligned}
\frac{\partial T_{T 2}^{\prime}}{\partial t}= & -u_{s, T 2}^{\prime} \frac{\partial \bar{T}_{E}}{\partial x}-\bar{v}_{s, T} \frac{\partial T_{T 2}^{\prime}}{\partial y}-\bar{w}_{s, T}\left(T_{T 2}^{\prime}-T_{50, T}^{\prime}\right) \\
& -\alpha T_{T 2}^{\prime}+\kappa \nabla^{2} T_{T 2}^{\prime}+F^{\prime} / \rho c_{p} H .
\end{aligned}
$$

In this case, the shallow water dynamics anomalies influence the SST only through the temperature of upwelled water.

(iii) Simulations with the three simplified ocean models for SST

These three different SSTs were computed by time integration forward from imposed initial SST conditions from ECMWF on 1 January of the El Niño that precedes each persistent cold state. Ocean model parameters are as in Seager et al. (2019). The Laplacian diffusion coefficient is $4 \times 10^{4} \mathrm{~m}^{2} \mathrm{~s}^{-1}$ and the surface heat flux damping time scale $\left(\alpha^{-1}\right)$ is 200 days. Results are shown in Fig. 8 and should be compared to the actual SST evolution shown in Fig. 3. For the case with ECMWF currents, upwelling and $T_{50}$ (top row) the onset, duration, and termination of the cold states in 1983-86 are well simulated and the division of the cold state into three stages with maximum cooling is also captured. However, SST cooling is located too far east and is also too weak. The same successes and failures are evident in the simulation of the 1998-2002 event. The 2010-14 event was different in that it had a warm interruption in 2012 and this is simulated by the simple model with ECMWF circulation and $T_{50}$, but the continuation of the cold state after this is not simulated and instead the modeled SST warms.

Using the simple ocean model with currents, upwelling and $T_{50}$ from the linear shallow water dynamics plus a frictional 


\section{Thermocline anomalies in TCOM forced with global $\tau$ anomalies (contours) and equatorial $\tau^{x}$ anomalies (colors)}
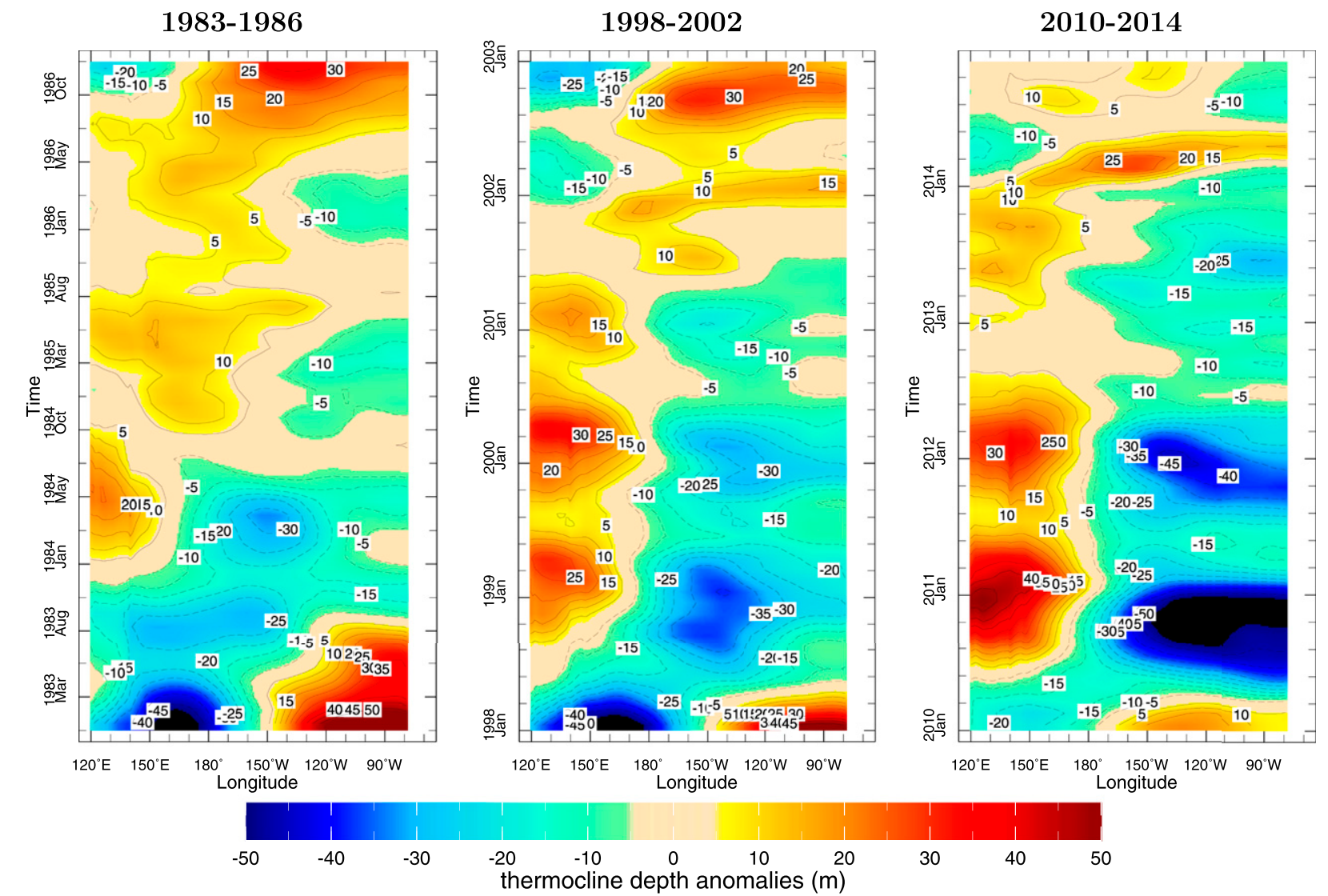

FIG. 7. The thermocline depth anomalies (m) simulated by the ocean model with global wind stress forcing (contours) and equatorial zonal wind stress anomalies only (colors).

Ekman layer the model reproduces the successes and failures when using ECMWF ocean data. However in the 1983-86 event the strength of cooling in the east-central equatorial Pacific is reduced. Notably, in this case with simulated circulation, the cold state in 2010-14 correctly persists into 2013 unlike the case with ECMWF ocean data. This has been traced toward a tendency in the ECMWF data to an eastward zonal current anomaly at the equator, which causes warm advection. This is not created as a response to the zonal wind stress in the linear shallow water dynamics plus frictional Ekman layer and its dynamical origins in the reanalysis are unknown (and beyond the scope of this study).

Finally, we replace the zonal current anomaly from the complete ocean model with that simulated from a balance between friction and zonal wind stress at the equator as in Eq. (5). This is one simplification too far since the cold SST anomalies during the event are now much weaker than with the more complete model or with the observations. This indicates that the geostrophic zonal currents are important in the maintenance of the cold states. The easterly wind stress drives a westward current and cold advection. Also, the shoaled equatorial thermocline during cold states (and associated equatorial trough in sea level) causes a westward geostrophic current that augments the advective cooling. This makes clear that thermocline dynamics are important to the cold states via both the influence on the temperature of upwelled water and zonal currents.

\section{MAINTENANCE OF WIND STRESS AND PRECIPITATION ANOMALIES DURING COLD STATES}

The ocean modeling work has made clear that the SST anomalies during the cold states are maintained by wind stress anomalies that drive anomalies in thermocline depth and zonal currents on the equator. For maintenance of the thermocline anomalies that matter, we suspect it is only the zonal wind stress near the equator that matters. Hence the next step is to see what drives the near-equatorial zonal wind stress anomalies. Figure 9 shows the precipitation and zonal wind stress anomalies simulated by the atmosphere model (TCAM) when driven by the observed SSTs and should be compared against observed values in the right column of Fig. 3. The characteristic features of cold states-easterly wind stress anomalies and negative precipitation anomalies 
Simplified Equation - SST anomalies $5^{\circ} S-5^{\circ} N$ average

Using ECMWF $u^{\prime}, T_{50}^{\prime}, \bar{v}, \bar{w}$
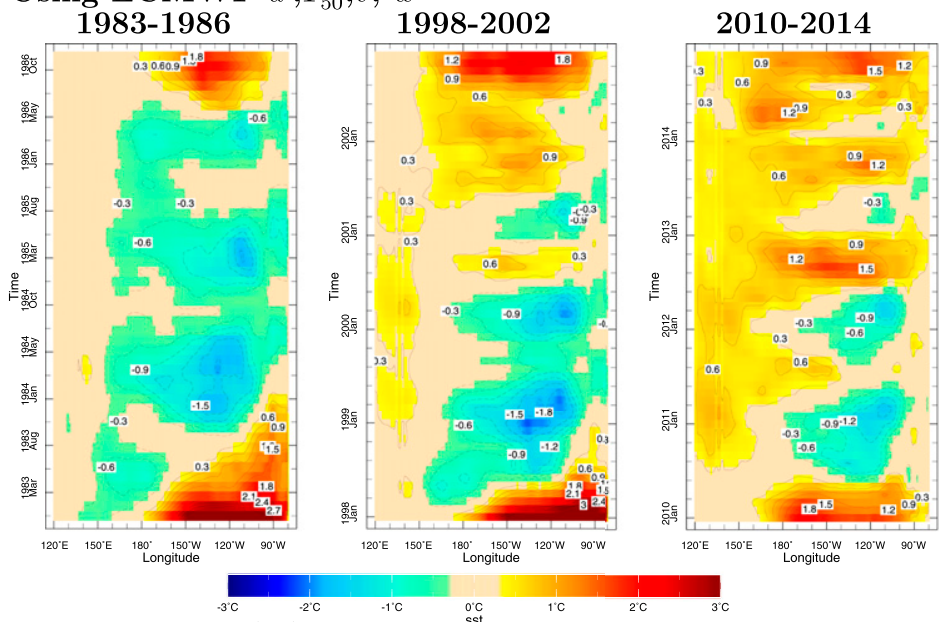

Using TCOM $u^{\prime}, h^{\prime}, \bar{v}, \bar{w}$
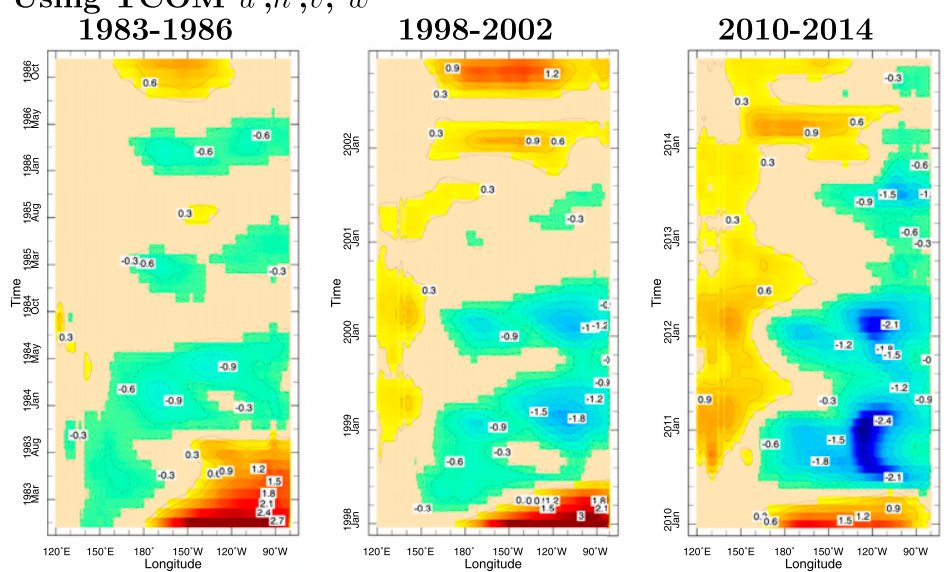

Using TCOM $\left(\tau^{x}\right)^{\prime}, h^{\prime}, \bar{v}, \bar{w}$

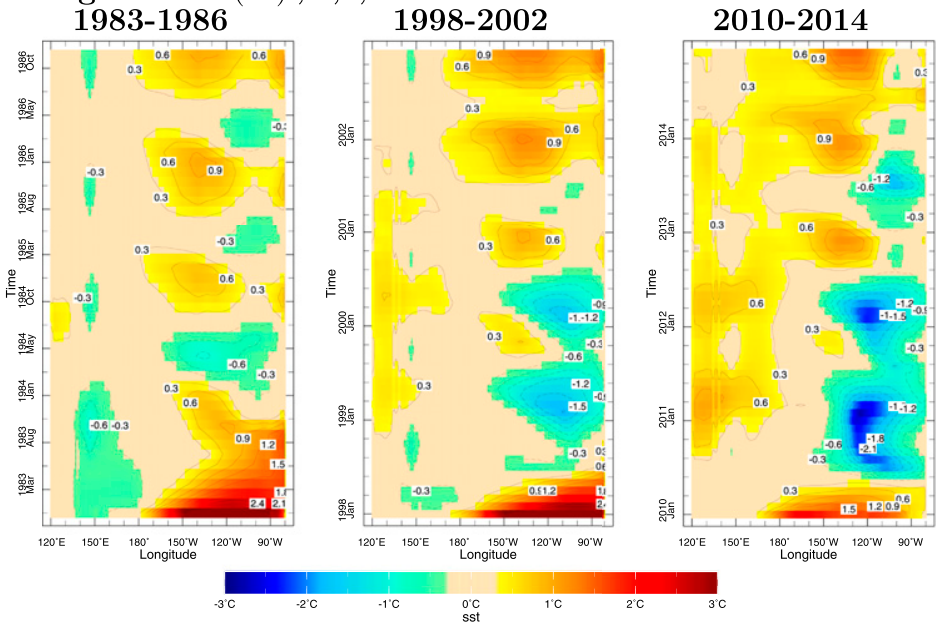

FIG. 8. Simplified models of the cold states. (top) Using currents and $T_{50}$ from ECMWF in the simplified SST equation, which is integrated forward from ECMWF initial conditions on $1 \mathrm{Jan}$ of the first year of the cold state. (middle) Replacing ECMWF currents and $T_{50}$ with those from the ocean model driven only by equatorial zonal wind stress anomalies. (bottom) Replacing the zonal current anomaly with that calculated from a balance of Rayleigh friction and zonal wind stress. 


\section{TCAM forced by ECMWF SSTs, $P$ (colors), $\tau^{x}$ (contours)}

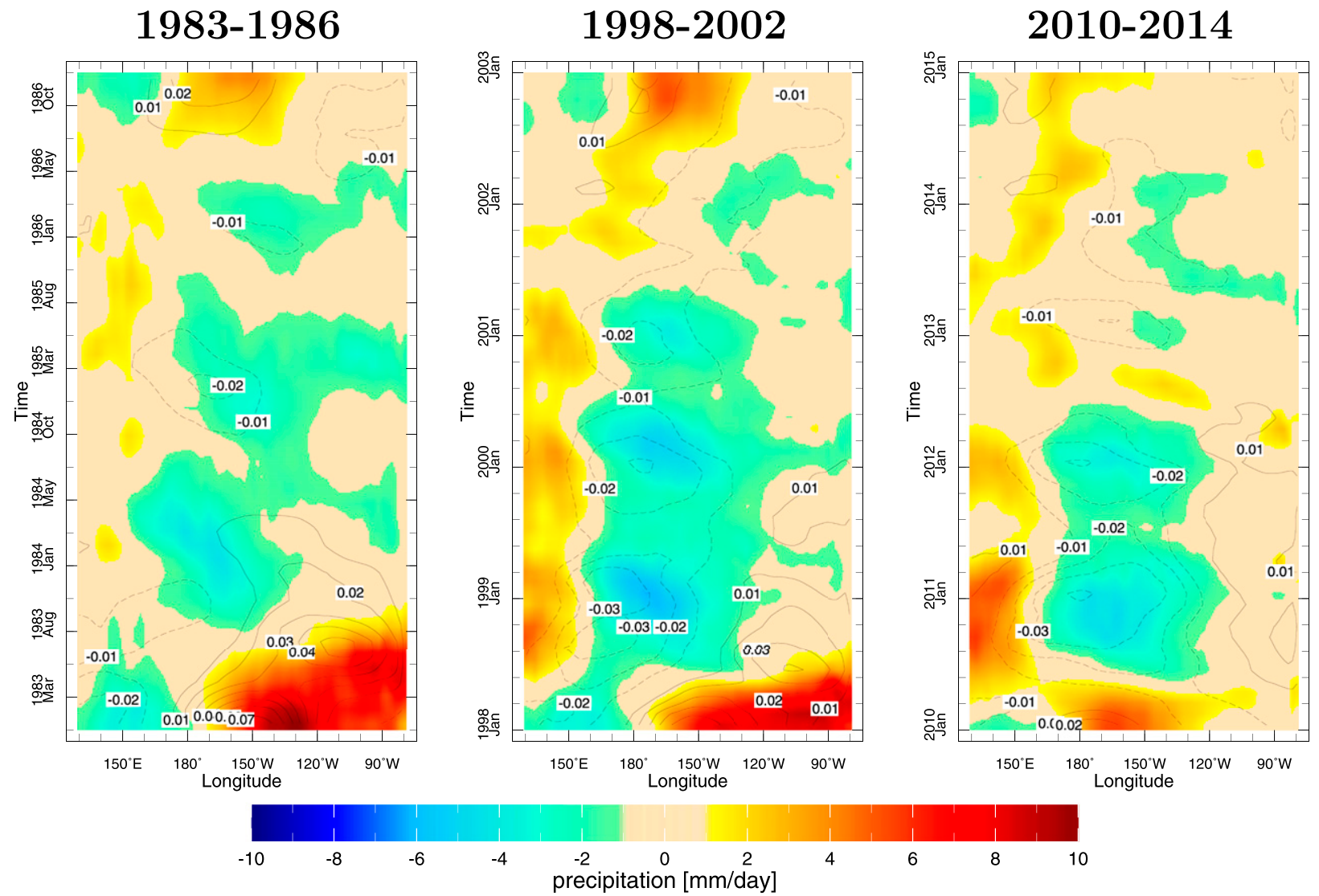

FIG. 9. The precipitation (color) and zonal wind stress (contours) anomalies computed by the atmosphere model forced by ECMWF SSTs for the three cold states.

over most of the equator with some positive anomalies over the far west-are simulated by the atmosphere model. Notable features that the model reproduces well are the relatively weak easterly anomalies in the 1983-86 event and the stronger easterlies with three maxima in the 1998-02 and 2010-14 events, and that these anomalies are in the western to central Pacific and are associated with collocated reduced precipitation. Atmosphere model easterly anomalies are however too far east in the most recent event. These results indicate that the essentials of the atmospheric conditions during cold states can be reproduced as a response to tropical Pacific SST anomalies.

\section{d. A simple model of atmosphere-ocean coupling that generates cold states}

So far we have shown that simplified models of the ocean and atmosphere can simulate fundamental characteristics of the ocean and atmosphere during cold states when driven by the observed state of the other fluid. What is not yet clear is whether this apparent success includes the features that are essential to the driving of the other fluid. The way to do this is to force the model of each fluid with the forcing simulated by the model of the other fluid. We do this two ways. In each method the ocean model is initialized on the 1 January preceding the cold state from a run of the model forced by observed wind stress over the entire period.

Method 1: Observed SST $\rightarrow$ atmosphere model winds $\rightarrow$ ocean model SST

1) Force the TCAM atmosphere model with observed SST.

2) Force the TCOM ocean model with wind stress from step 1.

3) Compare the SST from step 2 with the observed SST.

Method 2: Observed winds $\rightarrow$ ocean model SST $\rightarrow$ atmosphere model winds

1) Force the TCOM ocean model with observed wind stress.

2) Force the TCAM atmosphere model with SST from step 1.

3) Compare the stress from step 2 with the observed stress.

The simple TCOM ocean model we use in this is the one that uses the currents and thermocline depth calculated from the full shallow water dynamics plus surface Ekman layer, corresponding to $T_{T 1}$ and Eq. (4). The results of doing this are shown in Figs. 10, 11, and 12 for the three cold states with the top row for method 1 and the bottom row for method 2 . 


\section{3-1986}
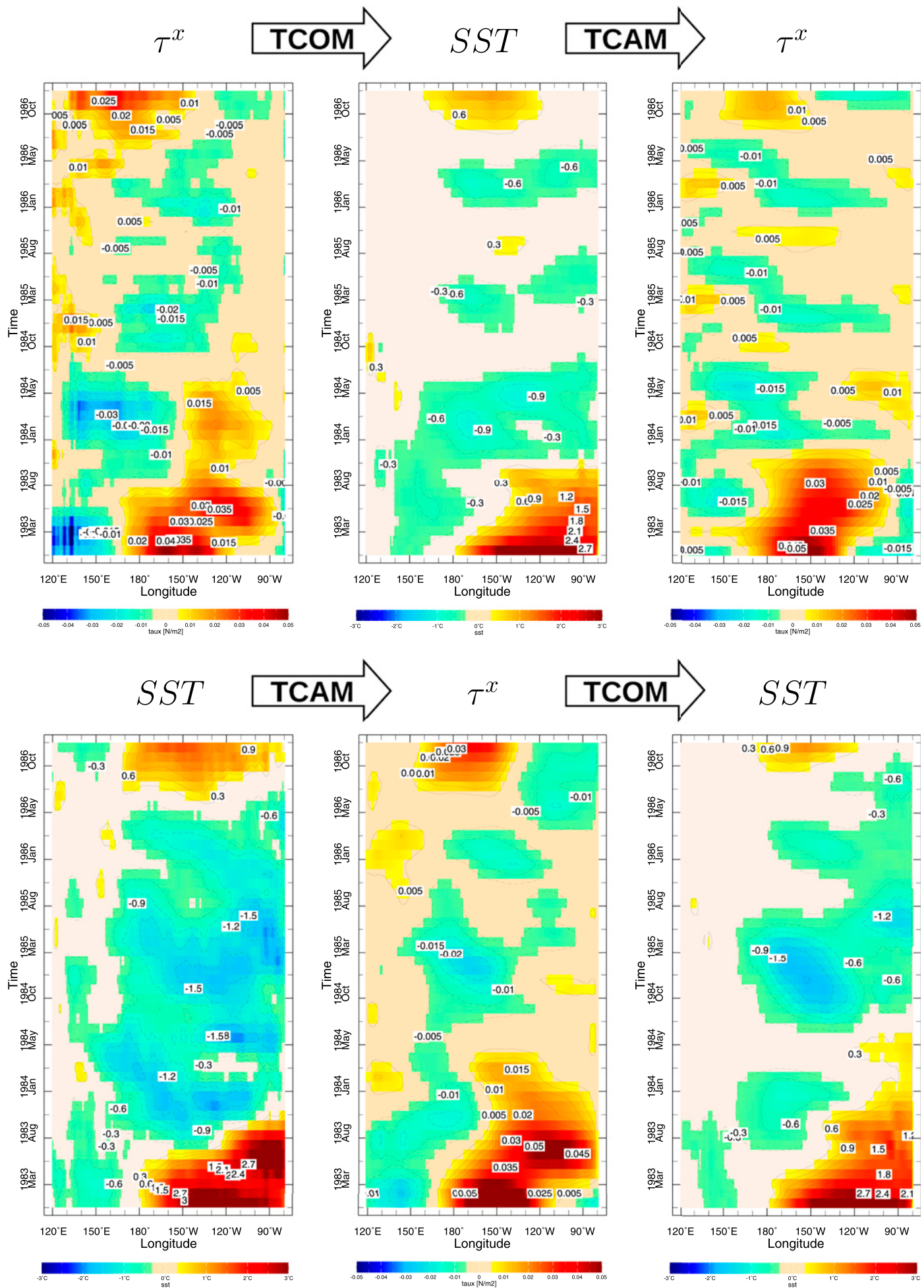

FIG. 10. Ocean and atmosphere modeling results for the 1983-86 cold state. (top, from left to right) The ECMWF zonal wind stress, the SST produced by the ocean model with simplified SST equation forced by this wind stress, and the zonal wind stress computed by the atmosphere model forced by the ocean model SST. (bottom, from left to right) The ECMWF SST, the zonal wind stress simulated by the atmosphere model forced by this SST, and the SST simulated by the ocean model and simplified SST equation when forced by the atmosphere model zonal wind stress. 
1998-2002

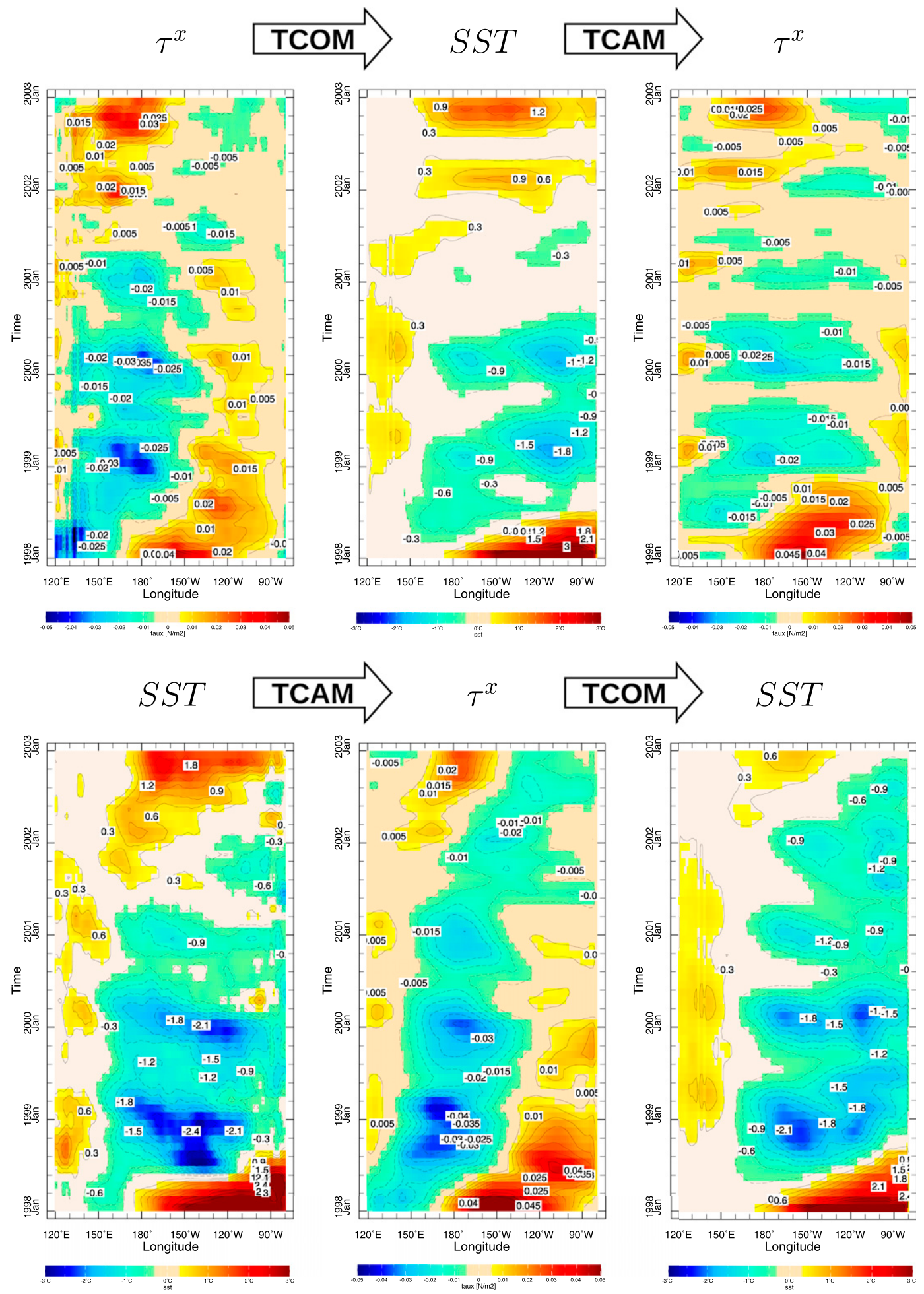

FIG. 11. As in Fig. 10, but for the 1998-2002 cold state. 


\section{0-2014}
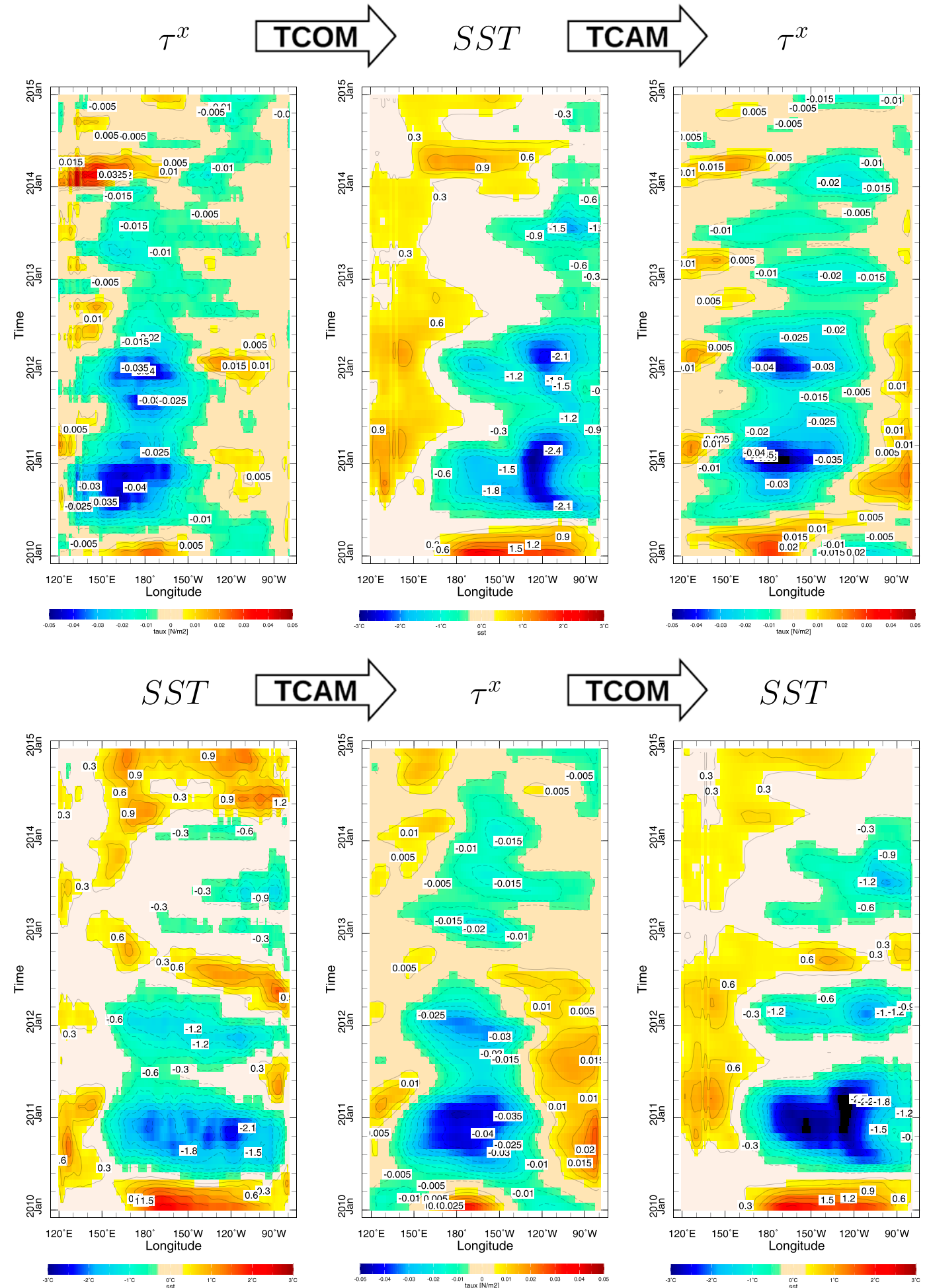

FIG. 12. As in Fig. 10, but for the 2010-14 cold state. 
The top row in Fig. 10 shows for the 1983-86 event the ECMWF wind stress, the SST modeled as a response to this, and the wind stress modeled as a response to the modeled SST. Certainly the two-step modeling does not lead to a perfect reproduction of the observed wind stress. However, the shift from westerly anomalies during the end of the 1982/83 El Niño to easterly anomalies over the western basin, the shift of the easterlies into the central basin, and then replacement by westerlies as the 1986/87 El Niño develops are all features that are simulated. Clearly, the SST anomalies simulated by the ocean model are too weak and, hence, the wind stress anomalies simulated as a response to the modeled SST anomalies are also too weak. Working the other way, in the lower row are shown the ECMWF SST, the zonal wind stress modeled as a response to this, and the SST modeled as a response to the modeled wind stress. Again, the two-step modeling leads to errors but the persistent cold anomaly with three minima is the key feature that is well simulated. In this case the atmosphere model simulates reasonable amplitude wind stress anomalies but, again, the SST anomalies then simulated are too weak.

Results are largely similar for the two other cold states (Figs. 11 and 12). Clearly the ocean model simulates too weak SST anomalies whether forced by ECMWF or atmosphere model-simulated wind stresses for the 1998-2002 state. Nevertheless, the simulation of SSTs and wind stresses as responses to model-simulated stresses and SSTs, respectively, does reproduce observed aspects of the timing, intra-event evolution, and spatial location of anomalies. One notable bias is the model cannot reproduce the westerly anomalies in the eastern basin from late 1998 to 2001.

The simulation of too weak SST anomalies by the ocean model is not general. For the 2010-14 state, the SST anomalies simulated by the ocean model are actually too strong. For this event, once more, the two-step modeling can reproduce the observed stress and SST anomalies - the initiation, intra-event evolution with three peaks, and termination-with notable fidelity.

All of these modeling results support the idea that the cold states are maintained by simple dynamical and thermodynamical processes internal to the tropical Pacific Oceanatmosphere system. However the two-step modeling process does not rule out possible influences from outside the tropical Pacific. This is because the atmosphere and ocean states used to begin the two-step modeling and initialize the ocean model may have such influences embedded.

\section{Discussion and conclusions}

Persistent multiyear cold states of the tropical Pacific Ocean drive hydroclimate anomalies worldwide, including drought in the extratropical Americas. Hence it is worth examining what causes these cold states. We have done that using ocean and atmosphere reanalyses from ECMWF and simple models of the tropical Pacific ocean and atmosphere. Our conclusions are as follows:

- During cold states, SST cooling is matched by the cooling of waters immediately below the mixed layer and a more tilted thermocline with shoaling in the east. In the atmosphere, precip- itation is shifted westward and there are anomalous easterly wind stresses along the central and eastern equatorial Pacific.

- Cold states are driven by anomalous ocean heat flux divergence and damped by increased heat flux from the atmosphere to ocean and heat flux convergence by subgrid-scale processes. Hence, they have a dynamical origin. The anomalous ocean heat flux divergence is contributed to importantly by both changes in circulation and thermal structure.

- The fundamental processes that contribute to the cold states are enhanced cold upwelling due to a shallowed thermocline, enhanced cold advection due to an anomalous westward equatorial current, and advection of the SST anomaly poleward by the mean meridional circulation. Subgrid-scale processes and surface heat flux anomalies damp the SST anomalies. These are the same set of processes familiar from studies of shorter time scale ENSO variability.

- The thermocline depth anomalies are governed essentially entirely by the zonal wind stress anomalies in the equatorial band.

- The zonal wind stress anomalies in the equatorial band, and associated precipitation anomalies, are a response to the tropical Pacific SST anomalies.

These results indicate a situation that allows the cold state to persist for multiple years. The ability to reproduce the relevant thermocline and current anomalies in terms of equatorial wind stresses indicates that ocean processes outside the equatorial Pacific are not important for maintaining the cold states. Of course, equatorial Pacific wind stresses could be influenced from outside the region (Cai et al. 2019). However, the ability to simulate them with only tropical Pacific SST forcing also indicates that atmospheric processes elsewhere are not important to the maintenance of the cold states. In prior work, Ramesh et al. (2016) used the Zebiak and Cane (1987) model of just the tropical Pacific atmosphere-ocean system to show that it could simulate analogs of the extended cold states of the 1870s, 1890s, 1930s, and 1950s. This lends more support to the idea that persistent cold states could arise from tropical Pacific coupling alone, but neither that work nor the work herein is conclusive in this regard.

The mechanisms for the generation of the SST and wind stress anomalies during the cold states are familiar from the Bjerknes feedback. However, unlike in Bjerknes' reasoning, they are not part of a positive feedback leading to ever-growing SST and stress anomalies. That positive feedback does occur in growing and decaying El Niño events as SST and stress anomalies change rapidly. As shown by Wyrtki (1985) and Zebiak (1989), during El Niño events, in addition to the positive Bjerknes feedback, there is a lagged negative feedback as heat is removed from the equatorial Pacific into the deeper tropics. Instead, during the cold states, there must be a steady balance between the positive Bjerknes feedback and some stabilizing negative feedback. The negative feedbacks must lead to heat flux convergence and surface heat flux anomalies closely balancing so that the equatorial heat content tendency is small. However, this does not last forever and all these cold states end usually with another El Niño event, typically after 2-4 years. Since the modeling here can simulate these terminations 
only accounting for coupling in the equatorial Pacific the termination might well not be due to influences from outside the region (e.g., the Indian Ocean or higher latitudes). Instead the cold states may hold within them the seeds of their inevitable destruction. The combination of observational analyses and simplified modeling used here appears fruitful to answer this question of why cold states persist but then finally end. The results suggest that the cause of the end of the cold states might arise from processes internal to the tropical Pacific but fall short of being able to prove that so the possibility of remote influences from elsewhere should also be considered.

Acknowledgments. This work was supported by NSF Award OCE-1657209. We thank three anonymous reviewers for useful critiques.

\section{REFERENCES}

An, S.-I., and F.-F. Jin, 2004: Nonlinearity and asymmetry of ENSO. J. Climate, 17, 2399-2412, https://doi.org/10.1175/15200442(2004)017<2399:NAAOE $>2.0$.CO;2.

Balmaseda, M. A., K. Mogensen, and A. T. Weaver, 2013: Evaluation of the ECMWF ocean reanalysis system ORAS4. Quart. J. Roy. Meteor. Soc., 139, 1132-1161, https://doi.org/ 10.1002/qj.2063.

Bjerknes, J., 1966: A possible response of the atmospheric Hadley circulation to equatorial anomalies of ocean temperature. Tellus, 18, 820-829, https://doi.org/10.3402/tellusa.v18i4.9712.

—, 1969: Atmospheric teleconnections from the equatorial Pacific. Mon. Wea. Rev., 97, 163-172, https://doi.org/10.1175/ 1520-0493(1969)097<0163:ATFTEP>2.3.CO;2.

Blumenthal, M. B., and M. A. Cane, 1989: Accounting for parameter uncertainties in model verification: An illustration with tropical sea surface temperature. J. Phys. Oceanogr., 19, 815-830, https://doi.org/10.1175/1520-0485(1989)019<0815: AFPUIM $>2.0 . \mathrm{CO} ; 2$.

Cai, W., and Coauthors, 2019: Pan-tropical climate interactions. Science, 288, eaav4236, https://doi.org/10.1126/SCIENCE. AAV4236.

Cane, M. A., and S. Zebiak, 1985: A theory for El Niño and the Southern Oscillation. Science, 228, 1085-1087, https://doi.org/ 10.1126/science.228.4703.1085.

Capotondi, A., and Coauthors, 2015: Understanding ENSO diversity. Bull. Amer. Meteor. Soc., 96, 921-938, https://doi.org/ 10.1175/BAMS-D-13-00117.1.

Cole, J. E., J. T. Overpeck, and E. R. Cook, 2002: Multiyear La Niña events and persistent droughts in the contiguous United States. Geophys. Res. Lett., 29, 1647, https://doi.org/10.1029/ $2001 G L 013561$.

Cook, E. R., R. Seager, M. A. Cane, and D. W. Stahle, 2007: North American droughts: Reconstructions, causes and consequences. Earth-Sci. Rev., 81, 93-134, https://doi.org/10.1016/ j.earscirev.2006.12.002.

Davey, M., and A. Gill, 1987: Experiments on tropical circulation with a simple moist model. Quart. J. Roy. Meteor. Soc., 113, 1237-1269, https://doi.org/10.1002/qj.49711347809.

Dee, D., and Coauthors, 2011: The ERA-Interim reanalysis: Configuration and performance of the data assimilation system. Quart. J. Roy. Meteor. Soc., 137, 553-597, https://doi.org/10.1002/qj.828.

DiNezio, P., and C. Deser, 2014: Nonlinear controls on the persistence of La Niña. J. Climate, 27, 7335-7355, https://doi.org/ 10.1175/JCLI-D-14-00033.1.
—, A. C. Clement, G. A. Vecchi, B. J. Soden, B. P. Kirtman, and S. Lee, 2009: Climate response off the equatorial Pacific to global warming. J. Climate, 22, 4873-4892, https://doi.org/ 10.1175/2009JCLI2982.1.

Dommenget, D., T. Bayr, and C. Frauen, 2012: Analysis of the nonlinearity in the pattern and time evolution of El Niño Southern Oscillation. Climate Dyn., 40, 2825-2847, https://doi.org/ 10.1007/s00382-012-1475-0.

Emile-Geay, J., and M. A. Cane, 2009: Pacific decadal variability in the view of linear equatorial wave theory. J. Phys. Oceanogr., 39, 203-219, https://doi.org/10.1175/2008JPO3794.1.

Frauen, C., and D. Dommenget, 2010: El Niño and La Niña amplitude asymmetry caused by atmospheric feedbacks. Geophys. Res. Lett., 37, L18801, https://doi.org/10.1029/2010GL044444.

Garreaud, R. D., and Coauthors, 2018: The 2010-2015 megadrought in central Chile: Impacts on regional hydroclimate and vegetation. Hydrol. Earth Syst. Sci., 21, 6307-6327, https:// doi.org/10.5194/hess-21-6307-2017.

Giannini, A., R. Saravanan, and P. Chang, 2003: Oceanic forcing of Sahel rainfall on interannual to interdecadal timescales. Science, 302, 1027-1030, https://doi.org/10.1126/science.1089357.

Gill, A. E., 1980: Some simple solutions for heat-induced tropical circulation. Quart. J. Roy. Meteor. Soc., 106, 447-462, https:// doi.org/10.1002/qj.49710644905.

Goddard, L., and N. E. Graham, 1997: El Niño in the 1990s. J. Geophys. Res., 102, 10 423-10 436, https://doi.org/10.1029/97JC00463.

Harris, I., P. D. Jones, T. J. Osborn, and D. H. Lister, 2014: Updated high-resolution grids of monthly climatic observations-The CRU TS3.10. Int. J. Climatol., 34, 623-642, https://doi.org/10.1002/joc.3711.

Herweijer, C., and R. Seager, 2008: The global footprint of persistent extratropical drought in the instrumental era. Int. J. Climatol., 28, 1761-1774, https://doi.org/10.1002/joc.1590.

,-- , and E. R. Cook, 2006: North American droughts of the mid to late nineteenth century: A history, simulation and implications for mediaeval drought. Holocene, 16, 159-171, https://doi.org/10.1191/0959683606hl917rp.

Hoerling, M. P., and A. Kumar, 2003: The perfect ocean for drought. Science, 299, 691-694, https://doi.org/10.1126/science.1079053.

— J. Eischeid, J. Perlwitz, X. Quan, T. Zhang, and P. Pegion, 2012: On the increased frequency of Mediterranean drought. J. Climate, 25, 2146-2161, https://doi.org/10.1175/JCLI-D-11-00296.1.

Huang, B., Y. Xue, H. Wang, W. Wang, and A. Kumar, 2012: Mixed layer heat budget of the El Niño in NCEP Climate Forecast System. Climate Dyn., 39, 365-381, https://doi.org/ 10.1007/s00382-011-1111-4.

Huffman, G. J., R. Adler, M. Morrissey, D. Bolvin, S. Curtis, R. Joyce, B. McGavock, and J. Susskind, 2001: Global precipitation at one degree daily resolution from multisatellite observations. J. Hydrometeor., 2, 36-50, https://doi.org/ 10.1175/1525-7541(2001)002<0036:GPAODD>2.0.CO;2.

Israeli, M., N. Naik, and M. A. Cane, 2000: An unconditionally stable scheme for the shallow water equations. Mon. Wea. Rev., 128, 810-823, https://doi.org/10.1175/1520-0493(2000) $128<0810$ :AUSSFT $>2.0$. CO;2.

Johnson, N. C., and S. Xie, 2010: Changes in the sea surface temperature threshold for tropical convection. Nat. Geosci., 3, 842-845, https://doi.org/10.1038/ngeo1008.

Kohyama, T., and D. Hartmann, 2017: Nonlinear ENSO warming suppression (NEWS). J. Climate, 30, 4227-4251, https:// doi.org/10.1175/JCLI-D-16-0541.1.

Latif, M., R. Kleeman, and C. Eckert, 1997: Greenhouse warming, decadal variability or El Niño? An attempt to understand the 
anomalous 1990s. J. Climate, 10, 2221-2239, https://doi.org/ 10.1175/1520-0442(1997)010<2221:GWDVOE > 2.0.CO;2.

Lyon, B., and D. DeWitt, 2012: A recent and abrupt decline in the East African long rains. Geophys. Res. Lett., 39, L02702, https://doi.org/10.1029/2011GL050337.

MacDonald, G. M., 2007: Severe and sustained drought in southern California and the west: Present conditions and insights from the past on causes and impacts. Quat. Int., 173-174, 87-100, https://doi.org/10.1016/j.quaint.2007.03.012.

McCabe, G. J., J. L. Betancourt, M. A. Palecki, and H. Hidalgo, 2008: Association of multi-decadal sea surface temperature variability with US drought. Quat. Int., 188, 31-40, https:// doi.org/10.1016/j.quaint.2007.07.001.

Meehl, G., and A. Hu, 2006: Megadroughts in the Indian monsoon region and southwest North America and a mechanism for associated multidecadal Pacific sea surface temperature anomalies. J. Climate, 19, 1605-1623, https://doi.org/10.1175/JCLI3675.1.

Menkes, C. E. R., J. G. Vialard, S. C. Kennan, J. Boulanger, and G. V. Madec, 2006: A modeling study of the impact of tropical instability waves on the heat budget of the eastern equatorial Pacific. J. Phys. Oceanogr., 36, 847-865, https://doi.org/10.1175/JPO2904.1.

Neelin, J. D., D. S. Battisti, A. Hirst, F.-F. Jin, Y. Wakata, T. Yamagata, and S. Zebiak, 1998: ENSO theory. J. Geophys. Res., 103, 14 261-14 290, https://doi.org/10.1029/97JC03424.

Newman, M., S. Shin, and M. A. Alexander, 2011: Natural variation in ENSO flavors. Geophys. Res. Lett., 38, L14705, https:// doi.org/10.1029/2011GL047658.

Ohba, M., and H. Ueda, 2009: Role of nonlinear atmospheric response to SST on the asymmetric transition process of ENSO. J. Climate, 22, 177-192, https://doi.org/10.1175/2008JCLI2334.1.

Okumura, Y., 2019: ENSO diversity from an atmospheric perspective. Curr. Climate Change Rep., 5, 245-257, https:// doi.org/10.1007/s40641-019-00138-7.

_- M. Ohba, C. Deser, and H. Ueda, 2011: A proposed mechanism for the asymmetric duration of El Niño and La Niña. J. Climate, 24, 3822-3829, https://doi.org/10.1175/2011JCLI3999.1.

Ramesh, N., M. Cane, R. Seager, and D.-E. Lee, 2016: Predictability and prediction of persistent cool states of the tropical Pacific Ocean. Climate Dyn., 49, 2291-2307, https:// doi.org/10.1007/S00382-016-3446-3.

Rayner, N., D. Parker, E. Horton, C. Folland, L. Alexander, D. Rowell, E. Kent, and A. Kaplan, 2003: Global analyses of sea surface temperature, sea ice, and night marine air temperature since the late nineteenth century. J. Geophys. Res., 108, 4407, https://doi.org/10.1029/2002JD002670.

Rodgers, K., P. Friederichs, and M. Latif, 2004: Tropical Pacific decadal variability and its relation to decadal modulation of ENSO. J. Climate, 17,3761-3774, https://doi.org/10.1175/15200442(2004)017<3761:TPDVAI >2.0.CO;2.

Schubert, S. D., M. J. Suarez, P. J. Pegion, R. D. Koster, and J. T. Bacmeister, 2004a: Causes of long-term drought in the United States Great Plains. J. Climate, 17, 485-503, https://doi.org/ 10.1175/1520-0442(2004)017<0485:COLDIT >2.0.CO;2.

,,,--- and,$- 2004 \mathrm{~b}$ : On the cause of the 1930s Dust Bowl. Science, 303, 1855-1859, https://doi.org/10.1126/ science.1095048.

Seager, R., 1991: A simple model of the climatology and variability of the low-level wind field in the tropics. J. Climate, 4, 164-179, https:// doi.org/10.1175/1520-0442(1991)004<0164:ASMOTC>2.0.CO;2.

_ 2007: The turn-of-the-century North American drought: Dynamics, global context and prior analogues. J. Climate, 20, 5527-5552, https://doi.org/10.1175/2007JCLI1529.1.
_- 2015: Decadal hydroclimate variability across the Americas. Climate Change: Multidecadal and Beyond, C.-P. Chang et al., Eds., World Scientific, 235-254.

_ S. E. Zebiak, and M. A. Cane, 1988: A model of the tropical Pacific sea surface temperature climatology. J. Geophys. Res., 93, 1265-1280, https://doi.org/10.1029/JC093iC02p01265.

— N. Harnik, W. A. Robinson, Y. Kushnir, M. Ting, H. P. Huang, and J. Velez, 2005a: Mechanisms of ENSO-forcing of hemispherically symmetric precipitation variability. Quart. J. Roy. Meteor. Soc., 131, 1501-1527, https://doi.org/10.1256/ qj.04.96.

—, Y. Kushnir, C. Herweijer, N. Naik, and J. Velez, 2005b: Modeling of tropical forcing of persistent droughts and pluvials over western North America: 1856-2000. J. Climate, 18, 4065-4088, https://doi.org/10.1175/JCLI3522.1.

—, M. Hoerling, S. Schubert, H. Wang, B. Lyon, A. Kumar, J. Nakamura, and N. Henderson, 2015: Causes of the 2011-14 California drought. J. Climate, 28, 6997-7024, https://doi.org/ 10.1175/JCLI-D-14-00860.1.

_- N. Henderson, M. Cane, H. Liu, and J. Nakamura, 2017: Is there a role for human-induced climate change in the precipitation decline that drive the California drought? J. Climate, 30, 10 237-10 258, https://doi.org/10.1175/JCLI-D-17-0192.1.

_, M. A. Cane, N. Henderson, D. Lee, R. Abernathey, and H. Zhang, 2019: Strengthening tropical Pacific zonal sea surface temperature gradient consistent with rising greenhouse gases. Nat. Climate Chang., 9, 517-522, https://doi.org/10.1038/s41558-019-0505-x.

Seth, A., K. Fernandes, and S. Camargo, 2015: Two summers of São Paulo drought: Origins in the western tropical Pacific. Geophys. Res. Lett., 42, 10 816-10 823, https://doi.org/10.1002/2015GL066314.

Timmermann, A., and Coauthors, 2018: El Niño-Southern Oscillation complexity. Nature, 559, 535-545, https://doi.org/ 10.1038/s41586-018-0252-6.

Trenberth, K., and T. J. Hoar, 1996: The 1990-1995 El NiñoSouthern Oscillation event: Longest on record. Geophys. Res. Lett., 23, 57-60, https://doi.org/10.1029/95GL03602.

Wang, C., C. Deser, J. Yu, P. DiNezio, and A. Clement, 2017: El Niño and Southern Oscillation (ENSO): A review. Coral Reefs of the Eastern Tropical Pacific, P. Glynn, D. Manzello, and I. Enochs, Eds., Springer, 85-106.

Wang, W., and M. J. McPhaden, 2000: The surface layer heat balance in the equatorial Pacific Ocean. Part II: Interannual variability. J. Phys. Oceanogr., 30, 2989-3008, https://doi.org/ 10.1175/1520-0485(2001)031<2989:TSLHBI >2.0.CO;2.

$\longrightarrow$, and — 2001: Surface layer temperature balance in the equatorial Pacific during the 1997-98 El Niño and 1998-99 La Niña. J. Climate, 14, 3393-3407, https://doi.org/10.1175/15200442(2001)014<3393:SLTBIT>2.0.CO;2.

Weiss, J. L., C. L. Castro, and J. T. Overpeck, 2009: Distinguishing pronounced droughts in the southwestern United States: Seasonality and effects of warmer temperatures. J. Climate, 22, 5918-5932, https://doi.org/10.1175/2009JCLI2905.1.

Wyrtki, K., 1985: Water displacements in the Pacific and the genesis of El Niño cycles. J. Geophys. Res., 90, 7129-7132, https:// doi.org/10.1029/JC090iC04p07129.

Zebiak, S. E., 1989: Oceanic heat content variability and El Niño cycles. J. Phys. Oceanogr., 19, 475-486, https://doi.org/10.1175/ 1520-0485(1989)019<0475:OHCVAE $>2.0 . C O ; 2$.

, and M. A. Cane, 1987: A model El Niño-Southern Oscillation. Mon. Wea. Rev., 115, 2262-2278, https://doi.org/ 10.1175/1520-0493(1987)115<2262:AMENO>2.0.CO;2. 